\title{
Portrait of the South East
}

By Peggy Causer and Neil Park, Office for National Statistics

\section{Key points}

- More people live in the South East than in any other region or country of the UK - 8.4 million people in 2009. Portsmouth is the most densely populated unitary authority outside London 5,000 people per sq $\mathrm{km}$ compared with an average for London of 4,900

- Housing in the South East is among the least affordable, with the second highest prices of any English region (after London). In all but nine local authorities the ratio of lower quartile house prices to lower quartile earnings in 2009 was higher than the average for the country

- Around a third of the working-age population in the South East are qualified to level 4 or higher of the National Qualification Framework, the second highest proportion (after London)

- Three-quarters of working-age residents are in employment, the highest proportion of any region. Rates of self-employment are among the highest in the UK: in Rother (East Sussex) more than a fifth of the working population is self-employed

- Employees in the South East had the second highest earnings (after London) of $£ 514$ per week in April 2009, 5 per cent above the UK average. Almost a quarter of employee jobs are in the professional and business services and finance sector

- The value of the economy was $£ 177$ billion in 2009, the second highest region (after London). More than 330,000 businesses were located in the South East, almost as many as in London

- Life expectancy for males in the South East is the highest of any region at more than 79 years; for females the South East is joint highest with the South West at more than 83 years

\section{Introduction}

The South East is often described as 'A region of many contrasts and exciting history ...' It is the third largest region of England, covering more than 19,000 square kilometres (sq km) and constituting almost 8 per cent of the total area of the UK. However, it is the largest region by population being home to 8.4 million people, 14 per cent of the UK total. By contrast, Scotland covers almost a third of the total area $(78,000 \mathrm{sq} \mathrm{km})$, but is home to 8 per cent of the population.

The region is roughly 'L-shaped' and surrounds more than half of London at the southern and western boundaries. The South East also borders several other regions - South West, West Midlands, East Midlands and the East - as well as being the region of the UK closest to the continent of Europe. The New Forest in Hampshire is the most westerly local authority and Thanet (Kent) the furthest east, with Milton Keynes and the Isle of Wight being the most northerly and southerly authorities. 


\section{Map 1 South East: physical features}

Relief (metres)
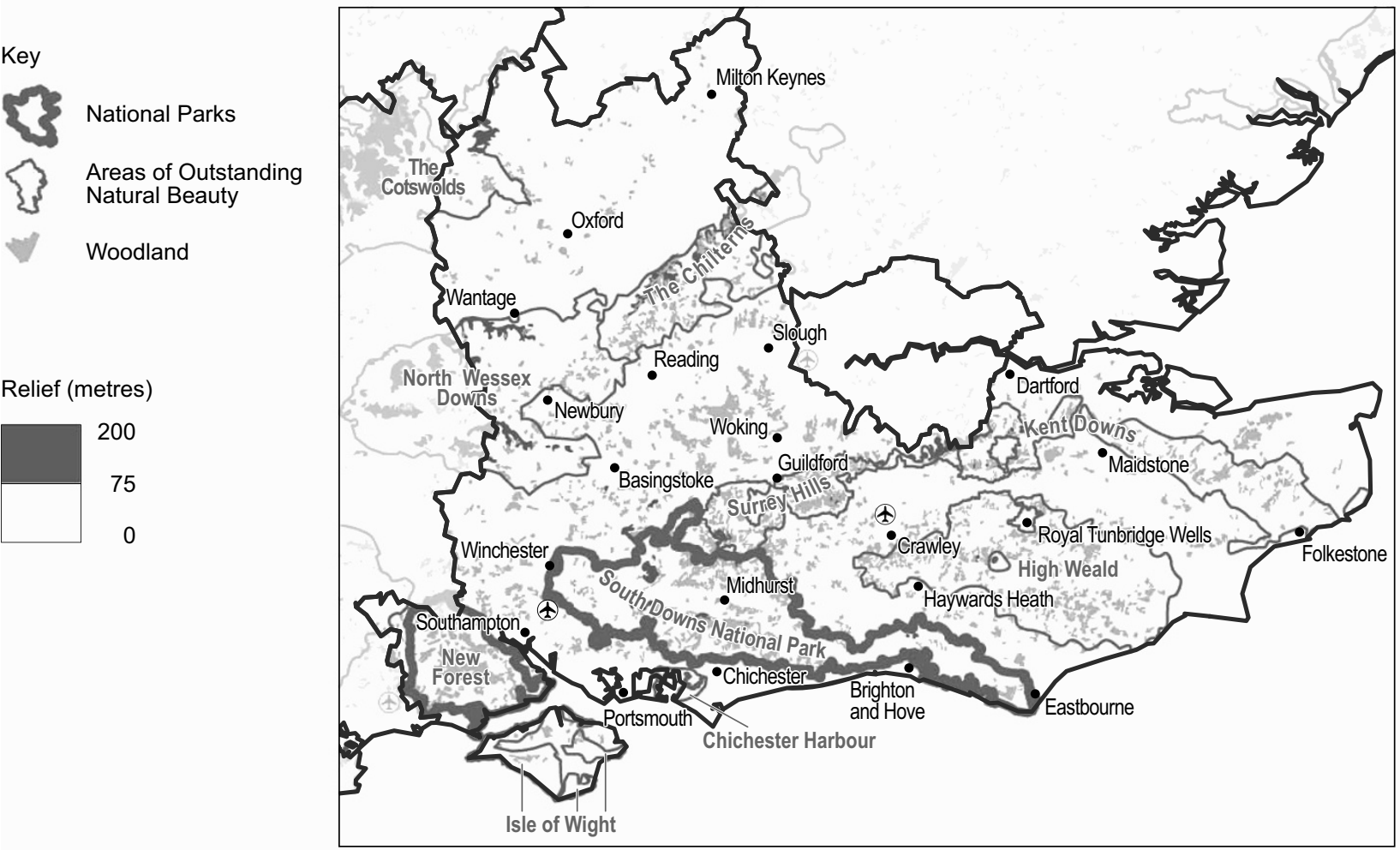

Map 2 South East: local or unitary authority, NUTS $2^{1}$ sub-regions and Rural/Urban Definition ${ }^{2}$

8

Regional boundary

Local or unitary authority ${ }^{3}$ boundary NUTS 2 boundary

Rural/Urban Definition ${ }^{4}$

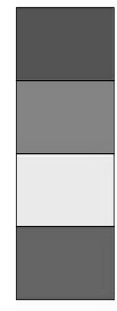

Urban population over 10,000-Less Sparse Town and Fringe-Less Sparse

Village, Hamlet and Isolated Dwellings-Less Sparse

Village, Hamlet and Isolated Dwellings -Sparse

$\begin{array}{ll}1 \text { Milton Keynes UA } & 14 \text { Epsom and Ewell } \\ 2 \text { Oxford } & \text { 15 Reigate and } \\ 3 \text { South Bucks } & \text { Banstead } \\ 4 \text { Windsor and } & \text { 16 Dartford } \\ \text { Maidenhead UA } & 17 \text { Gravesham } \\ 5 \text { Slough UA } & \text { 18 Tonbridge and } \\ 6 \text { Reading UA } & \text { Malling } \\ 7 \text { Wokingham UA } & \text { 19 Rushmoor } \\ 8 \text { Bracknell Forest } & \text { 20 Southampton UA } \\ \text { UA } & \text { 21 Eastleigh } \\ 9 \text { Runnymede } & \text { 22 Fareham } \\ \text { 10 Spelthorne } & \text { 23 Gosport } \\ \text { 11 Surrey Heath } & \text { 24 Portsmouth UA } \\ \text { 12 Woking } & \text { 25 Havant } \\ \text { 13 Elmbridge } & \text { 26 Crawley }\end{array}$

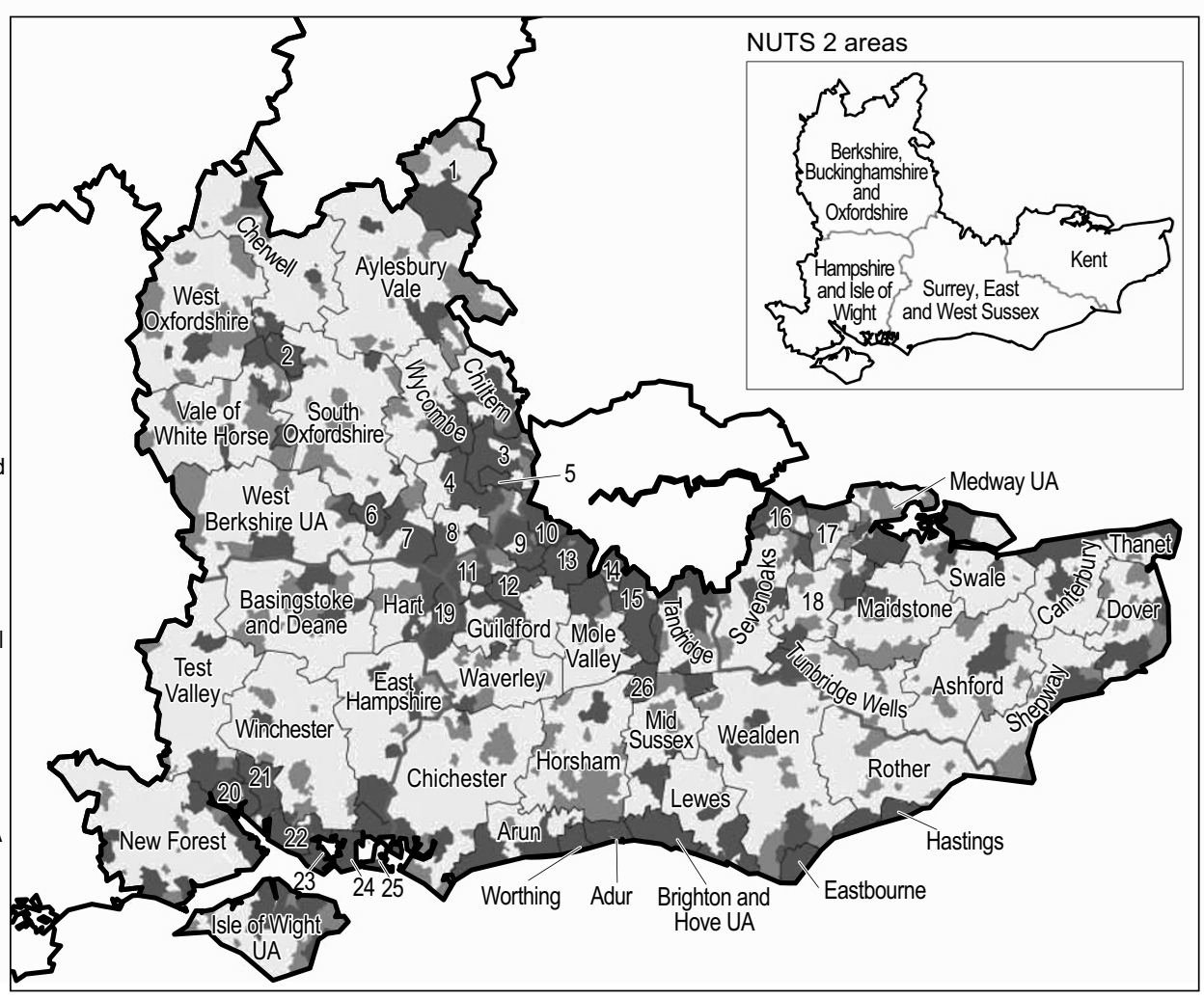

1 Nomenclature of Units for Territorial Statistics, level 2.

(c) Crown copyright and database right 2010. Ordnance Survey Licence 100019153.

2 By Lower Layer Super Output Area.

3 After the April 2009 re-organisation.

4 Two categories that do not appear in the South East have been excluded from the key: 'Urban population over 10,000-Sparse' and 'Town and Fringe-Sparse'. 
In places the South East is only 21 miles from the French shore and the region offers major international gateways for the rest of the UK. Connectivity of the South East is one of its major features - Gatwick (near Crawley in West Sussex) is the second largest airport in the UK, Southampton and Kent Airports also handle international travellers. There are major ports at Dover, Southampton and Portsmouth. More than a fifth (22 per cent) of England's motorway network is located in the South East. These gateways are vital for attracting foreign investments and for exporting goods and services produced throughout the UK. High speed rail links between the Channel Tunnel and London have increased the volume of traffic to the continent in recent years and provided a wealth of opportunities within the region.

Proximity to London and other capital cities provides a wide variety of business, cultural and leisure opportunities and also encourages national and international tourism to the region. The South East was the second most popular destination, after London, for international tourists with 13 per cent of the total, equivalent to 33 million tourist nights in 2008. The South East also received the second highest number (after the South West) of domestic tourists with 13 per cent of UK tourist nights being spent in the region. It is anticipated that the impact of the forthcoming Olympic Games will be a considerable boost for the region. The region's attractions include sites of historic interest and rural areas with quaint villages. The South East has been home to famous writers such as Charles Dickens and Jane Austen, politicians such as Winston Churchill, scientists and engineers such as Charles Darwin and Isambard Kingdom Brunel. The Royal Horticultural Society gardens at Wisley; Wakehurst Place (in West Sussex); Oxford; and castles at Windsor and Leeds (Kent); together with Runnymede in Surrey (site of signing the Magna Carta in 1215) are also located in the region.

There are often considered to be three distinct zones within the South East - an inner core which surrounds London and in parts is indistinguishable from the capital city; an extensive coastal area which includes both industrial and residential parts; and between these two zones a predominantly rural central band. Each of these zones has different characteristics and issues, with the influence of London and the proximity to Europe and further afield very strong. More than 410,000 people commute into London each day to work. This in turn has a ripple effect, drawing in others to provide a workforce for towns and cities throughout the region. The South East does not have very large cities like other regions, but is characterised by several regional hubs and market towns. There are seven 'cities' in the region, with the districts in which they are located ranging from Brighton and Hove with 256,000 people to Chichester the smallest with 113,000.

Diversity is a word which describes the South East, both in terms of its people and landscape. The quality of life in many parts of the region is good, although there are pockets of deprivation. Life expectancy in the South East is the highest, along with the South West, of any region in the country. Weekly earnings are second only to those received in London, and the South East has the highest employment rate of any region with one of the lowest unemployment rates.

The South East contains two National Parks (New Forest and the South Downs). It has considerable areas designated as of outstanding natural beauty (AONB), which together amount to around a third of the total area, the highest proportion of any region. In addition, the region has 5 per cent of the UK's heritage coast, part of a spectacular coastline covering 1,250 miles: consisting of iconic cliffs, estuaries, fortified ports and castles. As well as several world-renowned ports there are a myriad of small inlets and marinas stretching from Gravesend in Kent to Keyhaven and Lymington in the New Forest, providing leisure and tourism opportunities. Inland, running roughly 
west to east through the region, is the River Thames and the Surrey Hills and Chilterns cross the South East. It is the most wooded region with 15 per cent of the land area being covered by woodland. Sites of special scientific interest (SSSI) account for 7 per cent of the area. Despite these large areas of countryside, more than three-quarters of households live in urban areas in settlements of more than 10,000 people. Rural districts comprise more than half the total area of the South East, but are home to only 28 per cent of the population.

\section{Population}

In mid-2009 the population of the South East was 8.4 million, more than any other region or country in the UK and accounted for nearly 14 per cent of the total population (61.8 million).

The administrative geography of the South East comprises 7 counties (Buckinghamshire, East Sussex, Hampshire, Kent, Oxfordshire, Surrey and West Sussex) and 12 unitary authorities (UAs). Most of the UAs centre on larger towns and cities of the region such as Brighton and Hove, Southampton, and Portsmouth, but they also include some more rural areas such as the Isle of Wight and West Berkshire. The 7 counties are divided into 55 local authority districts ranging in area from Gosport (25 sq km) to Aylesbury Vale (903 sq km).

\section{Figure $3 \quad$ Mid-year population: by county and unitary authority}

South East, 2009

Thousands

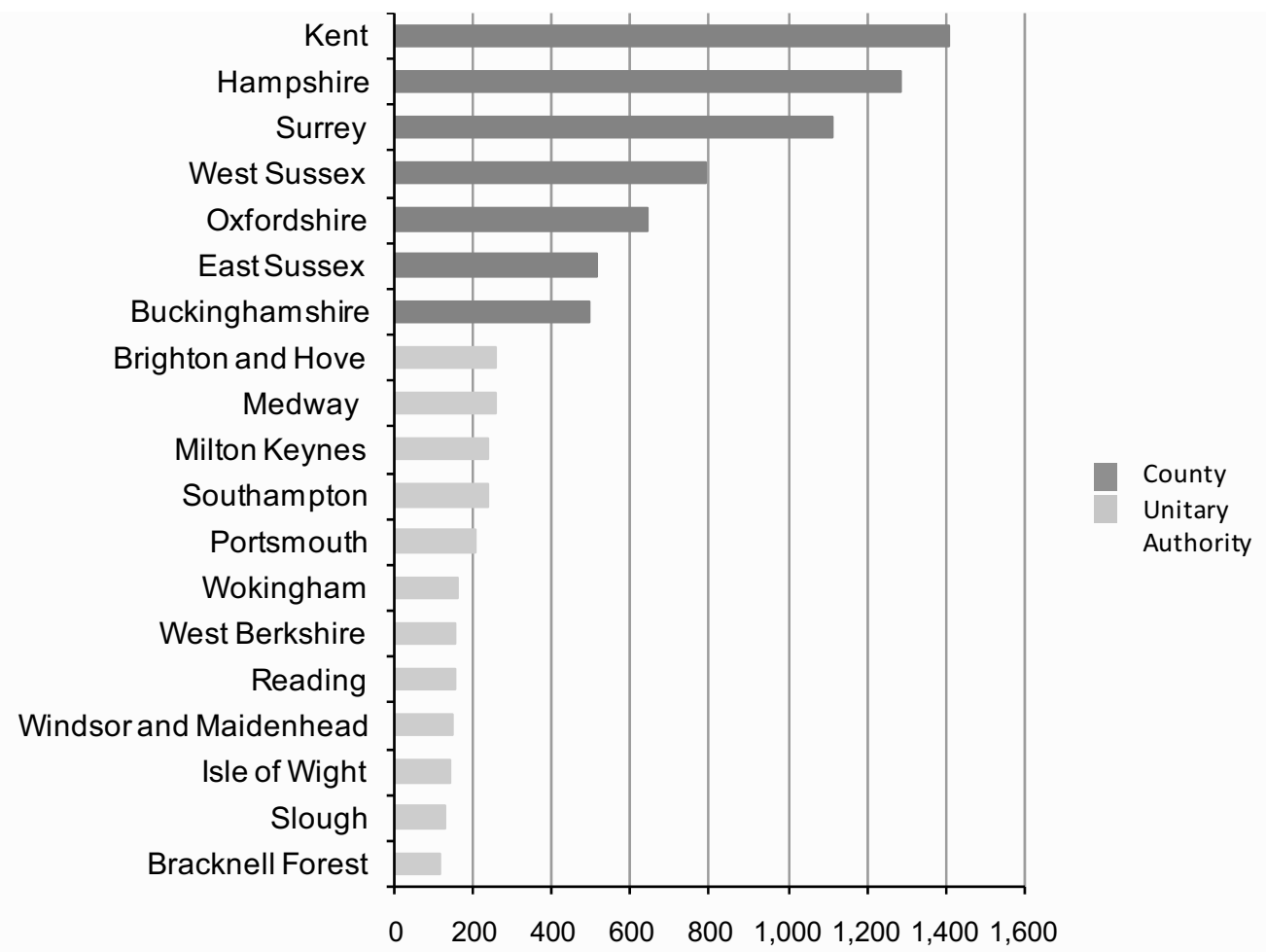

Source: Office for National Statistics

Figure 3 shows the mid-2009 populations of all 19 South East counties and unitary authorities. Of the 7 counties, Kent had the largest population at more than 1.41 million, followed by 
Hampshire (1.29 million) and Surrey (1.11 million). Buckinghamshire had the smallest population $(495,000)$, with East Sussex only slightly larger (512,000). The 12 UAs all had substantially lower populations than any of the counties, reflecting their smaller geographic size. The largest unitary authority in population terms is Brighton and Hove which had 256,000 residents in 2009; four other UAs had populations in excess of 200,000 - Medway, Southampton, Milton Keynes and Portsmouth. Bracknell Forest had the smallest population of just over 115,000.

Of the 55 local authority districts (lower tier authorities) the population was highest in New Forest (in Hampshire), Aylesbury Vale and Wycombe (both in Buckinghamshire) $(176,000,174,000$ and 164,000 respectively). The districts of Adur (West Sussex) and South Bucks (Buckinghamshire) had populations of less than 70,000 each.

\section{Figure 4 Mid-year population estimates: by 5-year age band and sex}

South East, 2009

Percentages

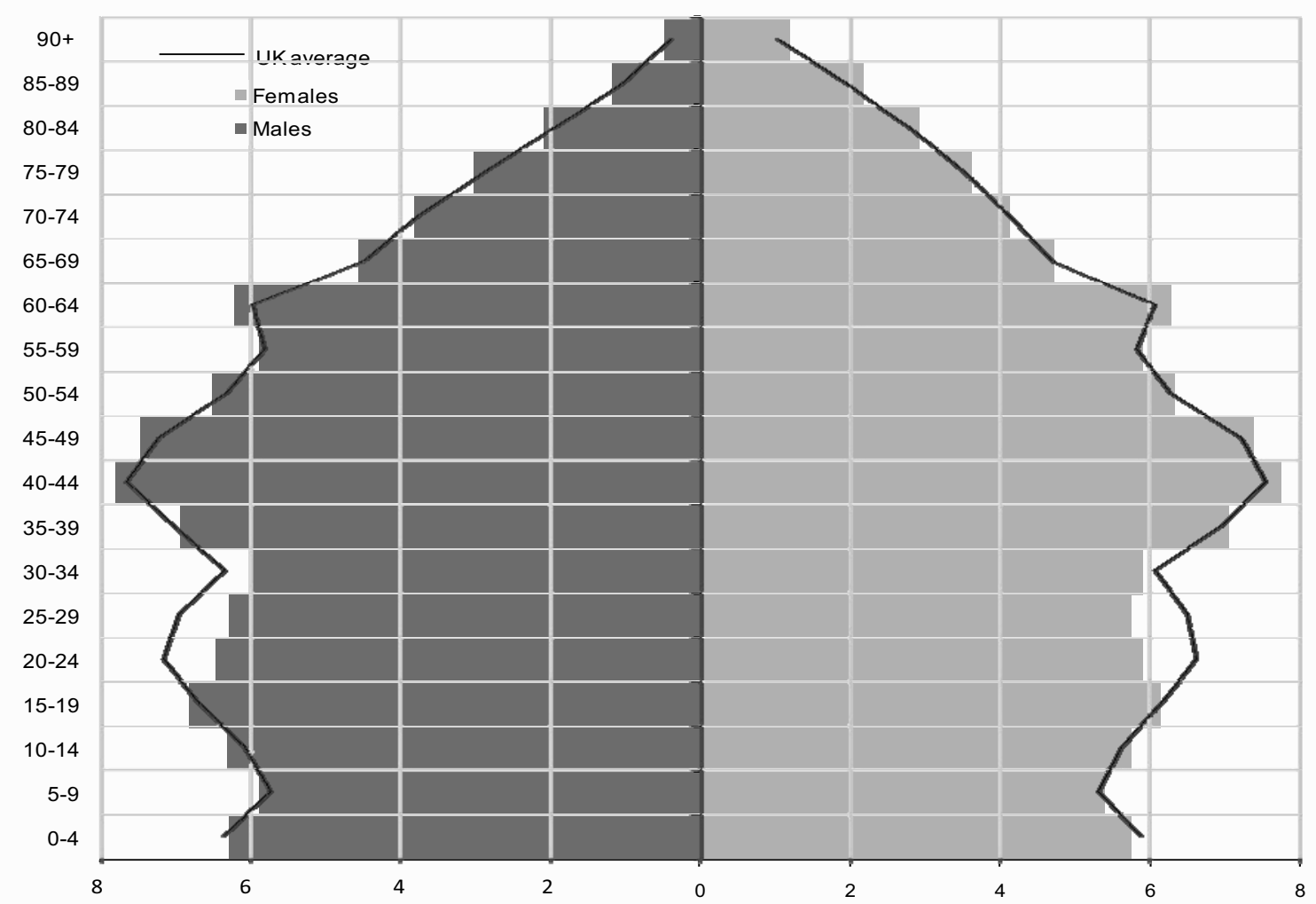

Source: Office for National Statistics

In 2009 the South East's population density was 440 people per sq $\mathrm{km}$, the third highest of the 9 English regions and substantially higher than the population density for the UK and England (255 people sq $\mathrm{km}$ and 398 per sq $\mathrm{km}$ respectively). Within the region the highest population densities, more than ten times the average for the region, were found in the urban authorities of Portsmouth and Southampton (5,100 and 4,800 people per sq km respectively). Indeed, Portsmouth has the highest population density of any unitary/local authority outside of London. Both Chichester (West Sussex) and West Oxfordshire have population densities that are less than a third of the regional average (143 per sq $\mathrm{km}$ ) reflecting the rural character of these areas. 
In mid-2009 the population structure of the South East showed some substantial differences from England (Figure 4). Most notably, a lower proportion of those living in the South East are aged between 20 and 34 than across the UK as whole. This is balanced by a higher proportion of people aged between 35 and 64 .

Map 5 shows the proportion of people over state pension age (60 for females/65 for males as was in force in 2009) for districts in the South East. This highlights the higher proportions of older people in the southern and particularly the coastal parts of the region. The local authority districts of Rother (East Sussex, 33 per cent) and Arun (West Sussex, 31 per cent) had substantially higher proportions of older people than the regional average (20 per cent). Conversely, the lowest proportions of older people were found in the centrally located urban areas of Slough, Oxford, Reading and Milton Keynes, where fewer than 14 per cent of residents in each area were above state pension age.

\section{Map 5 Percentage of the population who are of state pension age ${ }^{1}$ : by local or unitary authority², 2009}
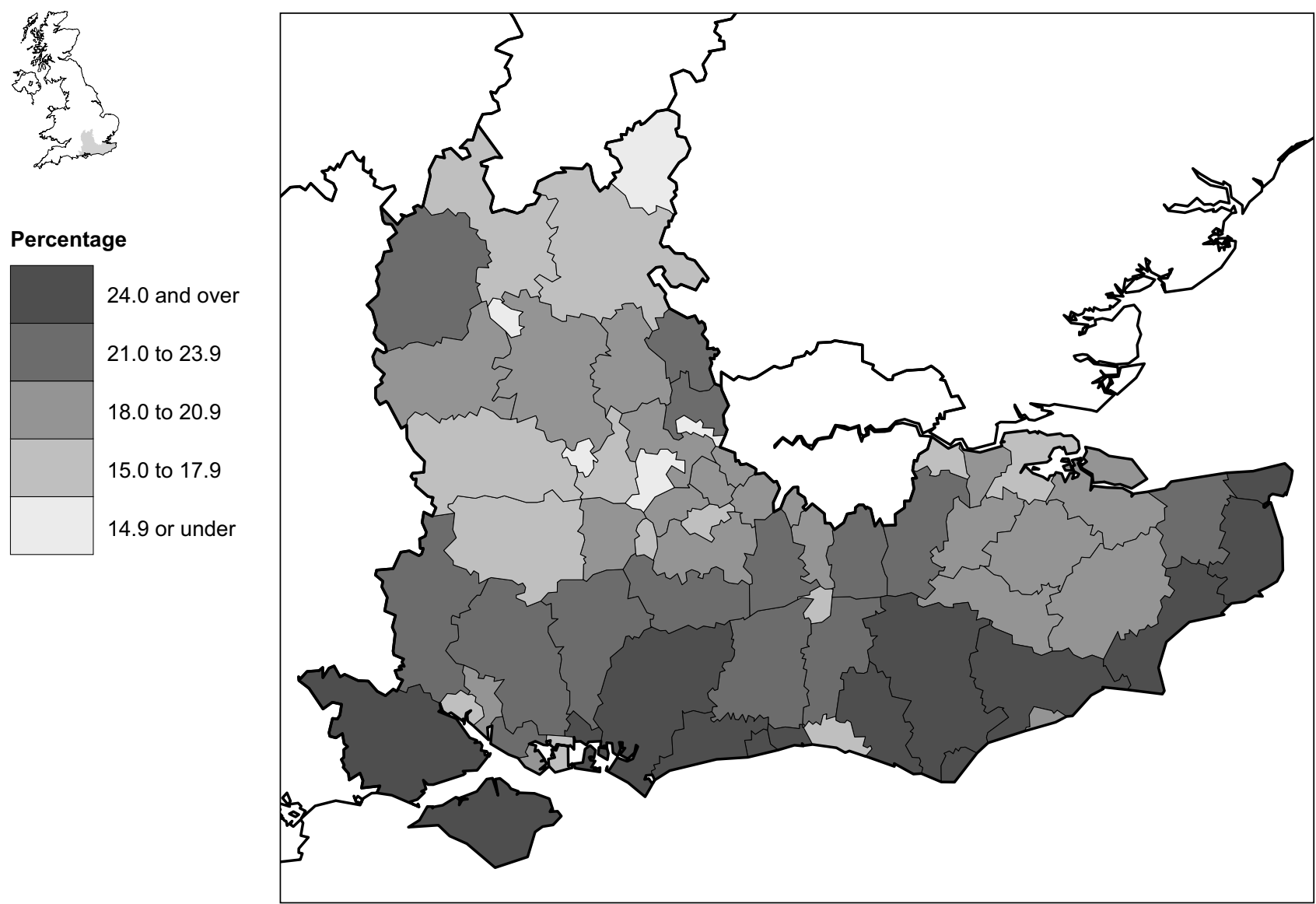

Percentage

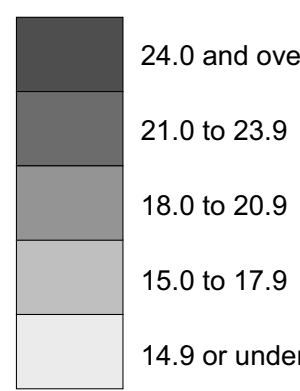

(c) Crown copyright and database right 2010. Ordnance Survey Licence 100019153

1 Men aged 65 or over, women aged 60 or over

2 For key to local authorities see Map A3.

Source: Office for National Statistics

Among the English regions, the South East has the fourth largest proportion of residents classified as non-White British (experimental population estimates by ethnic group, mid-2007). In 2007, 87 per cent of residents were White British, 3 percentage points higher than the average for England and Wales (83 per cent). The next largest ethnic groups in the region were White Other (4 per 
cent) and Asian or Asian British: Indian (1.7 per cent). The South East had the second largest population of residents classified as White Other $(318,000)$ outside London $(674,000)$. About 1 per cent of residents were born in India, with just under 1 per cent coming from Poland, South Africa, Germany and Ireland.

Several of the South East's more urban local authorities have high proportions of ethnic minorities, with the highest concentration in Slough. In 2007 about 44 per cent $(53,000)$ of Slough's residents were from groups other than White British, of which two-thirds (66 per cent) were Asian or Asian British. Oxford and Reading had the next highest proportions of ethnic minorities (28 and 24 per cent respectively).

\section{Figure $6 \quad$ Mid-year population for counties and unitary authorities: by urban/rural areas}

South East, mid-2008

Percentages

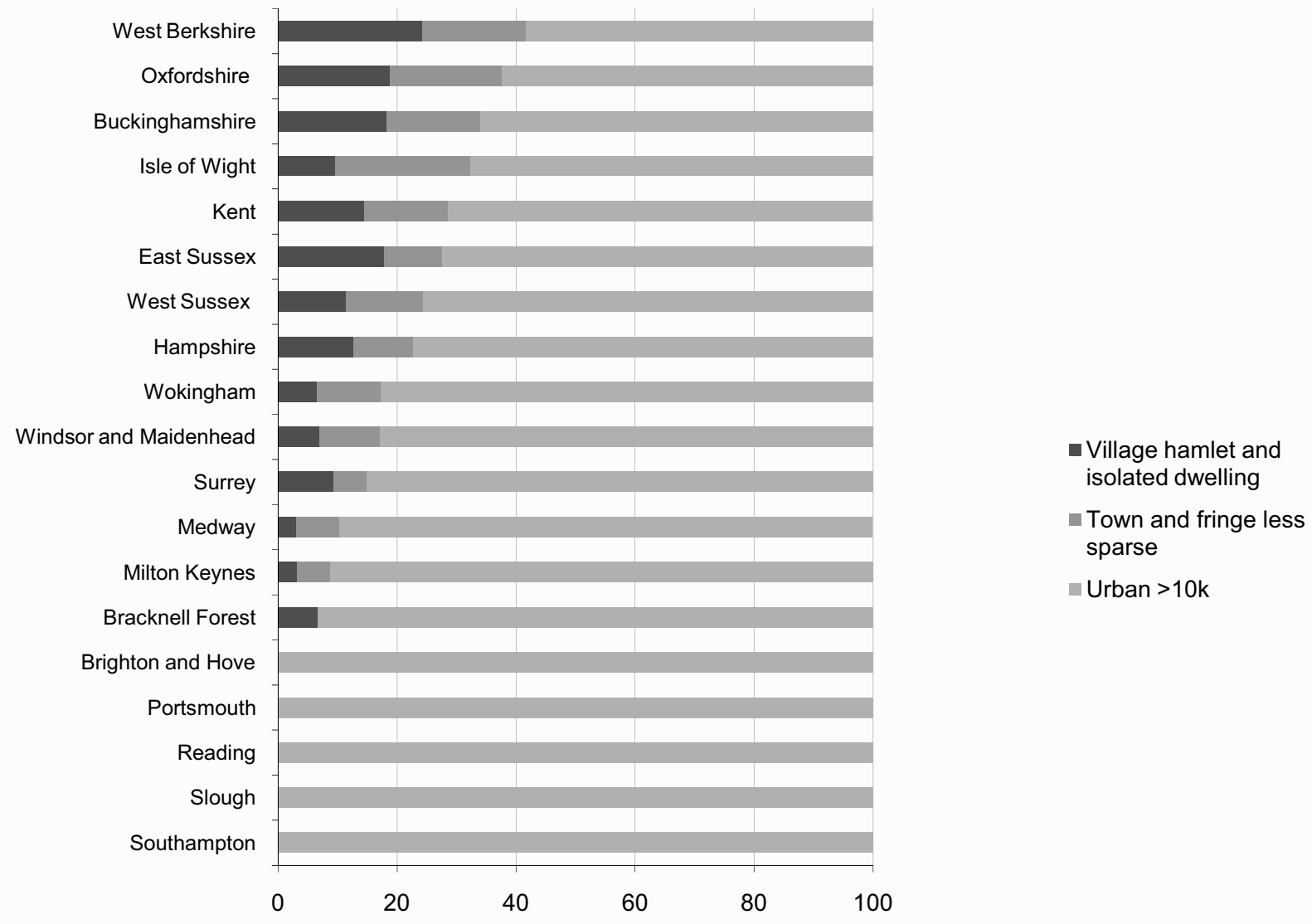

Source: Office for National Statistics

According to the Rural/Urban Definition defined at LSOA level, just over three-quarters (78 per cent in 2008) of South East residents live in towns or cities with a population of over 10,000, slightly lower than the average for England and Wales (80 per cent). Of the remaining population, about 10 per cent live in areas classified as 'town and fringe' and 11 per cent in 'villages, hamlets and isolated dwellings'. 
Among South East counties and unitary authorities there is considerable variation in the urban/rural distribution of the population (Figure 6): ranging from 100 per cent of people living in urban areas with a population of more than 10,000 in some unitary authorities to just 58 per cent in West Berkshire and 62 per cent in Oxfordshire. On the Isle of Wight nearly 25 per cent of residents live in areas classified as town and fringe, while 25 per cent of residents of West Berkshire live in villages, hamlets and isolated dwellings.

The number of people living in the South East increased by 1.07 million (15 per cent) between 1984 and 2009. With the exception of Havant (Hampshire) and only marginal change in Chiltern (Buckinghamshire), all of the South East's local authorities experienced population growth over the 25 years to 2009. Milton Keynes had the fastest growing population in England over this period: between 1984 and 2009 the population grew by 65 per cent, an increase of 94,000. Bracknell Forest and Ashford (Kent) were the next fastest growing areas with increases of 33 per cent and 29 per cent respectively over the period.

Between 2008 and 2009 the population of the South East increased by 0.8 per cent, (about 67,000 people), a slightly higher percentage increase than nationally. Only London and the East had higher percentage increases over this period ( 1.1 per cent and 0.9 per cent respectively). Twofifths (40 per cent) of the increase between 2008 and 2009 was due to natural change (the difference between births and deaths) with the remaining three-fifths (59 per cent) from migration and other changes. Across England and Wales the opposite was true, with natural change responsible for 57 per cent of the population increase.

\section{Figure $7 \quad$ Components of population change: by county and unitary authority}

South East, mid-2008 to mid-2009

Thousands

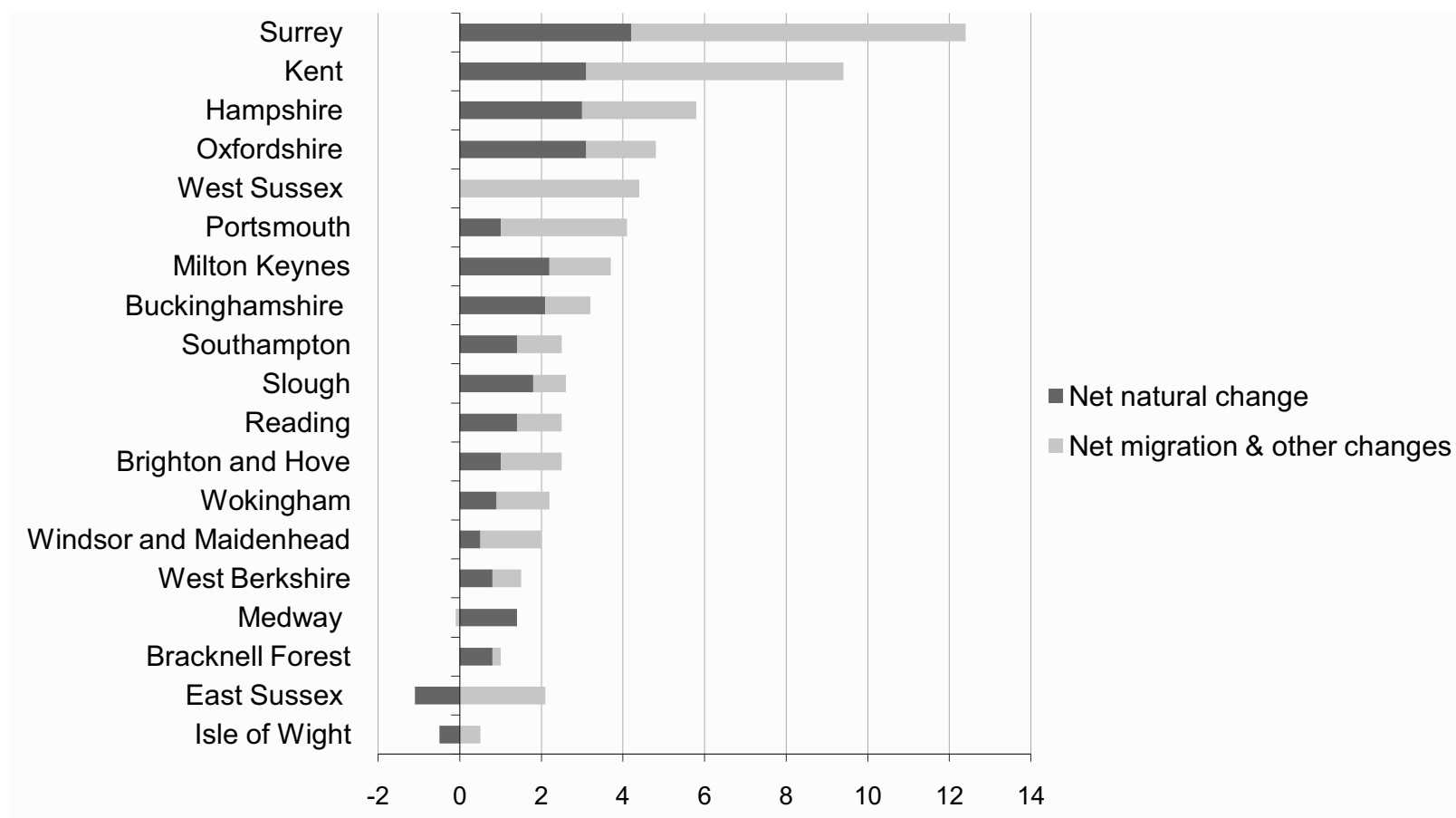

Source: Office for National Statistics 
Within the region the fastest rates of growth were in Portsmouth and Slough (2.1 per cent in each). Figure 7 shows components of change for the South East's counties and UAs. While all of these areas had population increases (except the Isle of Wight), several local authority districts saw reductions in their population between 2008 and 2009, the largest decreases being in Chiltern (0.4 per cent) and Rother (0.3 per cent).

The older age profile of the population living near the coast has a substantial effect on natural change; these areas tend to have fewer births and slightly more deaths. Rother for example, had the highest proportion of people aged over state pension age. This has a direct consequence on its crude birth and death rates, which were respectively the lowest and the highest in the South East (7.9 and 14.9 per 1,000 residents in 2008). Conversely, areas with younger age profiles had substantially higher birth rates and lower death rates, with the highest crude birth rate in Slough (21.4 per 1,000) and the lowest death rate in Bracknell Forest (Berkshire) and Hart (Hampshire) (both 6.1 per 1,000). Even in areas with younger populations, fertility rates varied widely, from 89.6 live births per 1,000 women aged between 15 and 44 in Slough and 75.9 in Milton Keynes to less than 50 in Canterbury and Oxford. The low fertility rates in Canterbury (Kent) and Oxford reflect the large numbers of young adults that are only temporarily resident in these areas, such as students.

\section{Figure $8 \quad$ Net migration ${ }^{1}$ : by region}

England, 2008

Thousands

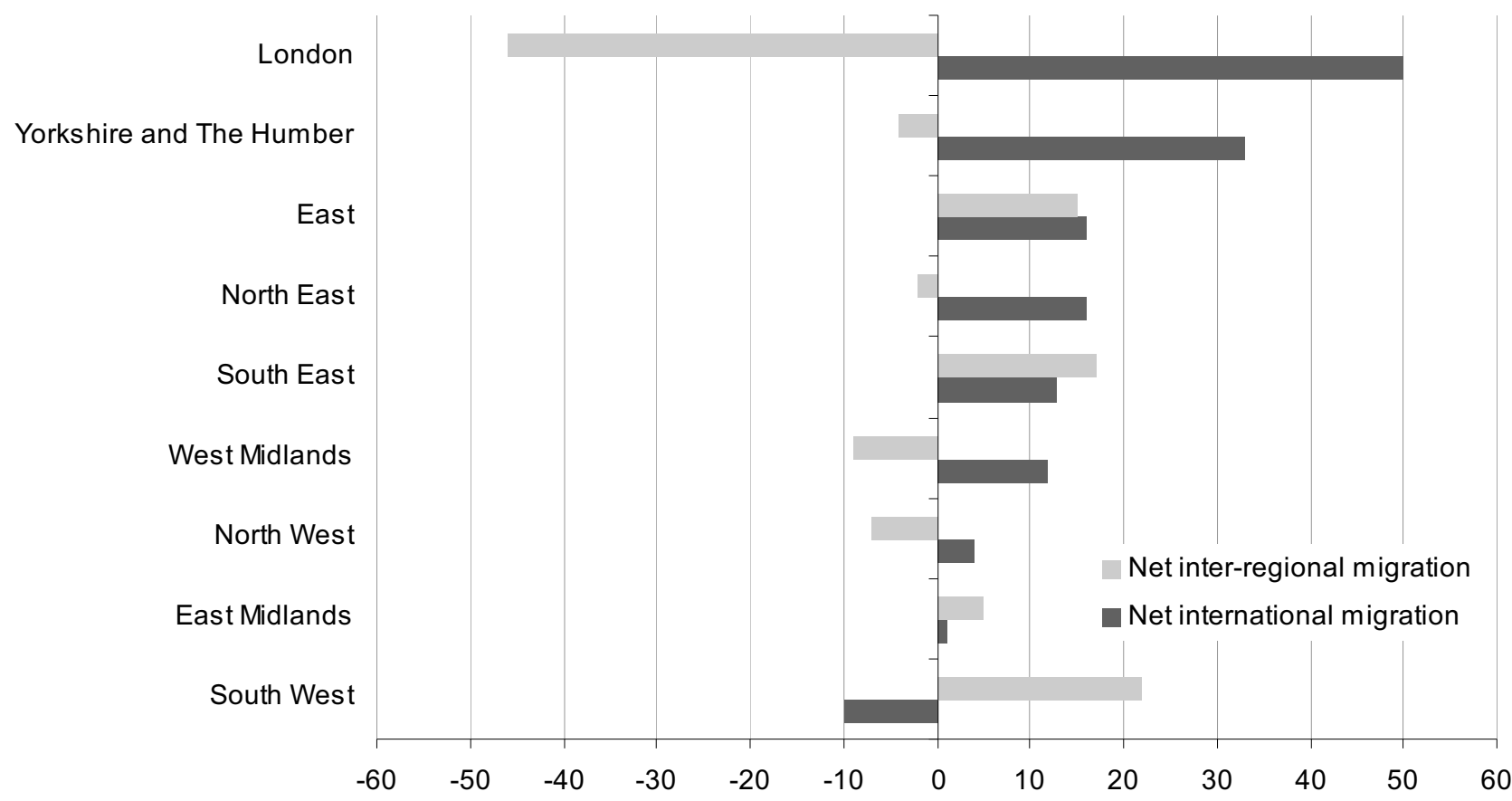

1 Net inter-regional migration of people moving from/to other regions of the UK and net international migration of people migrating from/to outside the UK.

Source: National Health Service Central Register; International Passenger Survey, Office for National Statistics; Home Office

Figure 8 shows that the South East had both net inter-regional $(+17,000)$ and net international migration $(+13,000)$ in 2008 . The South East had the second highest net inter-regional (internal) migration after the South West $(+22,000)$ but only the fifth highest net international migration. 
The South East population is projected to grow to just over 10 million by 2033, an increase of 20 per cent on 2008 and 2 percentage points more than England as a whole. As Figure 9 shows, most of the increase in population is expected to be accounted for by the increase in those aged above the current state pension age (64 per cent), with 23 per cent from those of working age and just 12 per cent from children.

\section{Figure $9 \quad$ Projected ${ }^{1}$ change in population: by 5 -year age band and sex}

South East, 2008 to 2033

Thousands

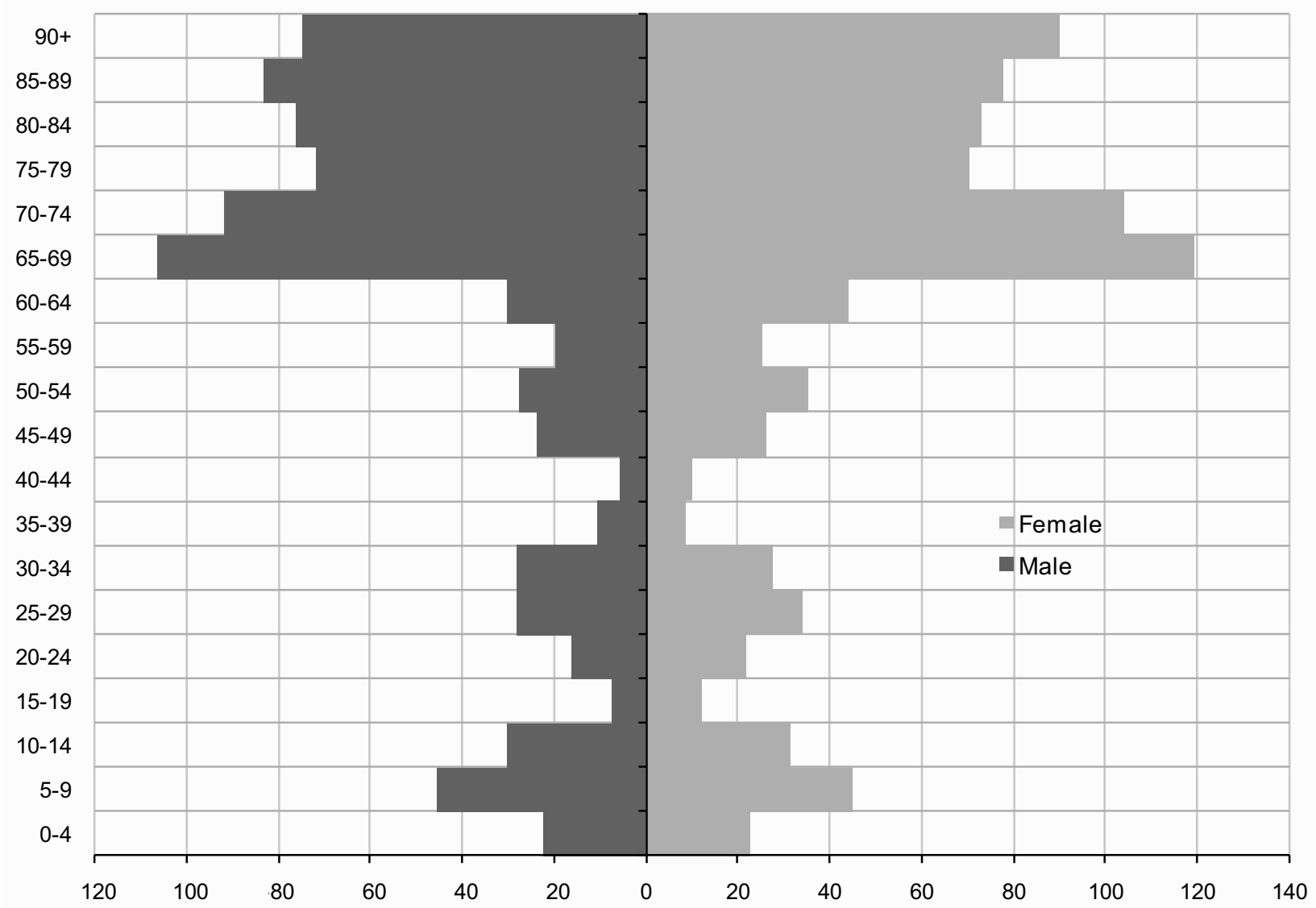

1 2008-based projections.

Source: Office for National Statistics

Dartford (32 per cent), Milton Keynes and Ashford (Kent) (both 31 per cent) are projected to have the largest percentage growth in population between 2008 and 2033. The lowest projected growth rates are in Havant and Wycombe (11 per cent in each). In all but eight of the South East's local authorities the number of older people is projected to grow by at least 50 per cent over the 25-year period, with the highest rate of change for this age group in Milton Keynes (121 per cent). The working-age population of seven local authorities is projected to decrease over the period. Dartford and Epsom and Ewell are the only local authorities where the working-age population is projected to grow by 20 per cent or more. 


\section{Households and housing}

In 2006 there were 3.45 million households in the South East, nearly 14 per cent of the Great Britain total. About 47 per cent contained a married couple, above the English average of 44 per cent. An additional 10 per cent of households included a cohabiting couple, while the proportion of single person households was lower than the English average (30 compared with 32 per cent).

The total number of households in the region is projected to rise to 4.43 million by 2031 , an increase of 980,000 households, reflecting a reduction in the average household size from 2.33 to 2.16 people as well as population increases. Projected changes indicate that the number of single person households is expected to be 1.61 million by 2026 , overtaking the number of married couple households. The number of cohabiting couple households is expected to more than double over the period 2001 to 2031 from 298,000 to 606,000 .

In 2008 there were 3.6 million dwellings in the South East, accounting for 16 per cent of England's dwelling stock. Approximately 16 per cent of dwellings in the region were flats or maisonettes, the second highest proportion (after London at 43 per cent). About 30 per cent of dwellings were detached houses or bungalows, 8 percentage points higher than the average for England.

Between 2007/08 and 2009/10 the number of new build completions in the South East fell by 22 per cent to 23,500. Despite this, the South East still accounted for the largest share of dwellings completed among the English regions in 2009/10 (21 per cent). The number of new dwellings completed for private enterprise fell by 29 per cent between these two years, however they still accounted for 76 per cent of the total in the South East. The proportion of completions for registered social landlords increased from 17 per cent to 24 per cent over the same period.

The median dwelling price in the South East was $£ 203,000$ in 2009, £33,000 (19 per cent) above the average for England. The district of Elmbridge in Surrey's 'stockbroker belt' had the highest median dwelling price in the region $(£ 363,000)$. The Buckinghamshire districts of Chiltern and South Bucks had the next highest median dwelling prices of $£ 345,000$ and $£ 341,000$ respectively. The lowest median dwelling prices were found in the urban coastal districts: Gosport (Hampshire) at $£ 139,000$ was closely followed by Hastings (East Sussex, $£ 143,000$ ), Medway (Kent, $£ 144,000$ ) and Portsmouth $(£ 145,000)$. In general, dwelling prices in the region are at their highest near London and at their lowest near the coast.

Median dwelling prices in the region fell by 6 per cent between 2008 and 2009 compared with a 2 per cent fall across England. In three districts - Elmbridge, Reigate and Banstead, and Surrey Heath (all in Surrey) - median dwelling prices increased or remained stable between 2008 and 2009 (less than 1 per cent change). In six districts the median dwelling price fell by more than 10 per cent, with the biggest decrease of 13.1 per cent in Crawley (West Sussex).

Housing in the South East is among the least affordable in England. A commonly used indicator of housing affordability is the ratio of lower quartile house prices to lower quartile earnings (see Box 1). In 2009 lower quartile houses and flats in the South East were only slightly more affordable to local workers than those in London, with ratios of 7.7 and 8.0 respectively. Between 2000 and 2007 the ratio of lower quartile house prices to lower quartile earnings in the region increased from 5.4 to 8.9, before decreasing between 2007 and 2009. Within the South East house price 
affordability varies considerably, with the most affordable districts being Portsmouth and Dover (ratios of 5.4 and 5.8 respectively) and the least affordable districts Elmbridge and Tandridge (Surrey) where lower quartile house prices were nearly 12 times lower quartile earnings.

\section{Box 1 Measuring Housing Affordability}

An important indicator of housing affordability is the ratio of lower quartile house prices to lower quartile incomes.

The lower quartile value for a particular area is determined by ranking all prices or incomes in ascending order and identifying the value below which 25 per cent fall.

The statistics used for lower quartile income are workplace based annual full-time individual earnings from the Annual Survey of Hours and Earnings (ASHE). The ASHE is based on a 1 per cent sample of employee jobs in April of a given year. It does not cover the self-employed nor does it cover employees not paid during the reference period.

Lower quartile house prices are based on Land Registry data for the first two quarters of a given year. Each ratio is calculated by dividing the house price by the income. Data for local authorities in England and Wales can be accessed on the Communities \& Local Government (CLG) website:

www.communities.gov.uk/housing/housingresearch/housingstatistics/housingstatisticsby/housingmark et/livetables/

\section{Map 10 Ratio ${ }^{1}$ of lower quartile house prices to lower quartile earnings: by local or unitary authority², 2009}

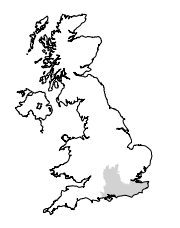

Lower quartile house prices ratio
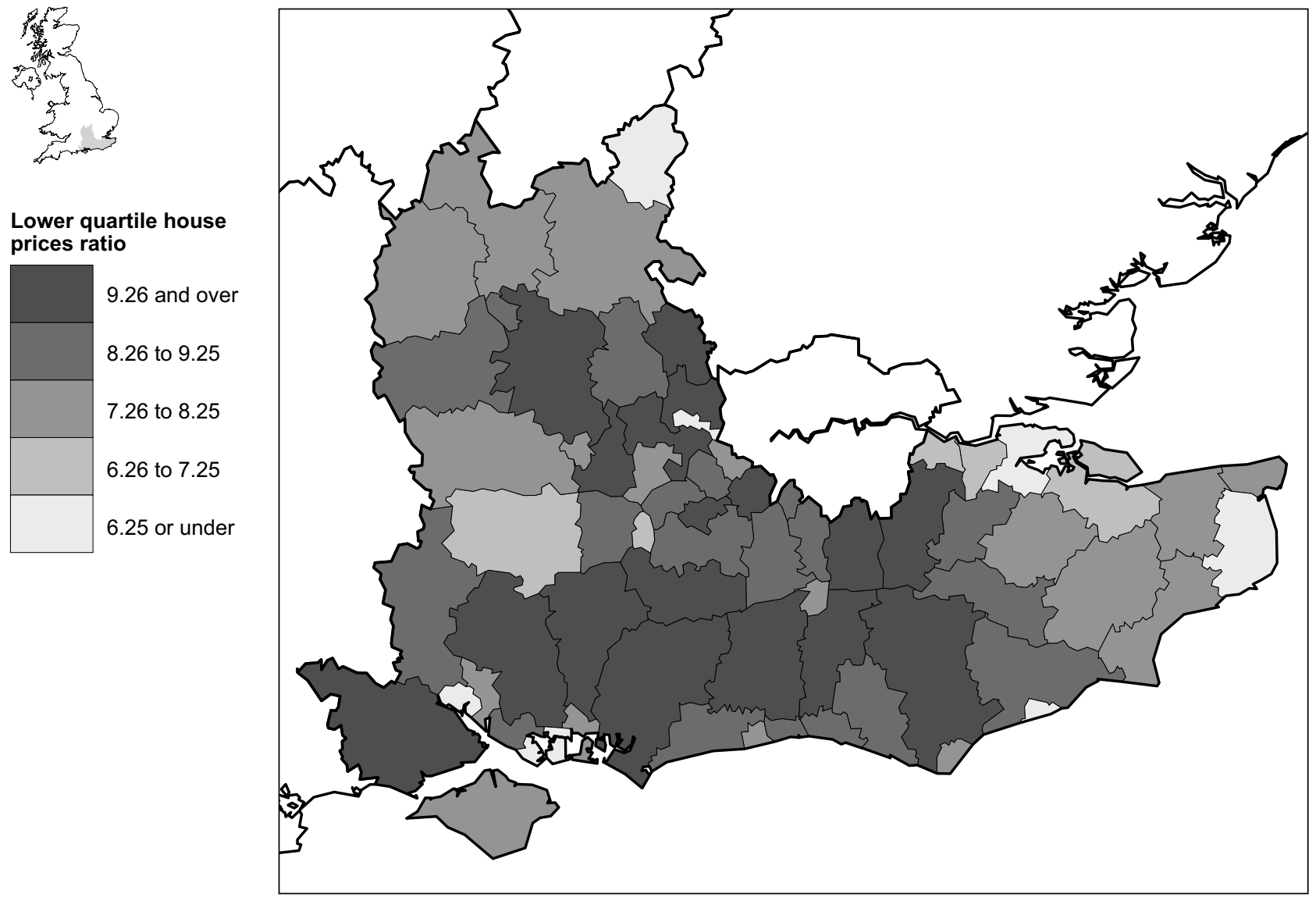

(c) Crown copyright and database right 2010. Ordnance Survey Licence 100019153.

$1 \mathrm{~A}$ higher ratio means less affordable house prices. See Box 1 for further details of the ratio.

2 For key to local authorities see Map A3.

Source: Annual Survey of Hours and Earnings (Office for National Statistics); Communities and Local Government; HM Land Registry 
In all but eight local authorities the ratio of lower quartile house prices to lower quartile earnings was higher than the average for England of 6.28 (Map 10).

\section{Education and skills}

Three-quarters (75.1 per cent) of pupils at Key Stage 4 in maintained schools in the South East achieved five or more GCSEs at grades $A^{*}$ to $C$ or equivalent in $2009 / 10$, according to provisional results. This was close to the average for England: the highest regional proportion was 79.0 per cent in the North East. However, looking at GSCE results that include the subjects of English and Mathematics the proportion of pupils in the South East achieving high grades was well above the national average at 57.1 per cent, and only second to the proportion of pupils in London who achieved 57.3 per cent. Within the South East, the proportion was highest in Buckinghamshire with

\section{Figure 11 Pupils ${ }^{1}$ achieving grade $\mathbf{A}^{*}$ to $\mathrm{C}$ at GCSE: by local education authority ${ }^{2}$}

South East, academic year 2009/10

Percentage points difference from England average

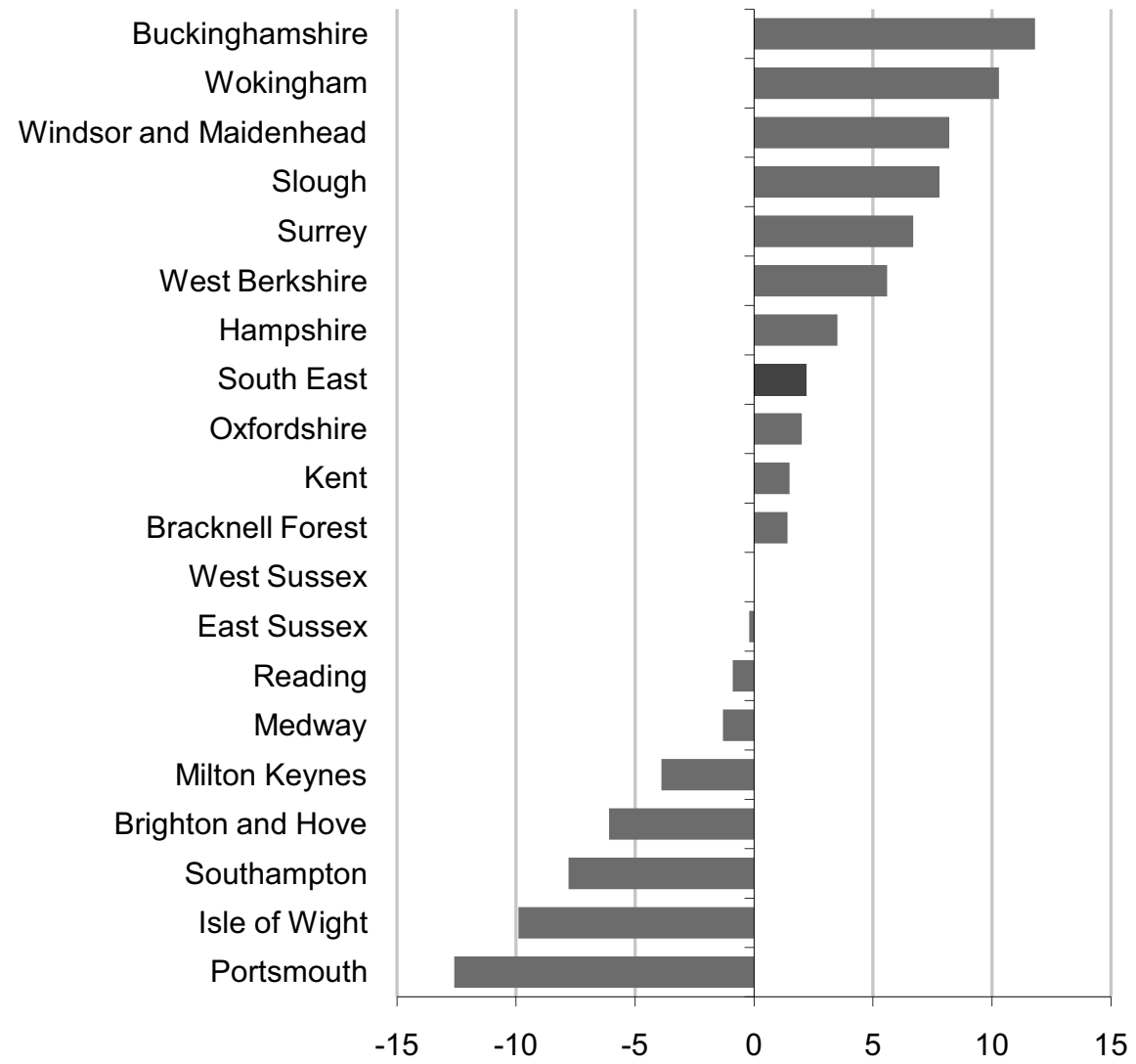

Note: England average (maintained sector) $=54.9$ per cent

1 Key stage 4 pupils achieving five or more GCSE grades $A^{*}$ to $C$ including English and Mathematics. Includes attempts and achievements in previous academic years.

2 Local authority figures do not include pupils recently arrived from overseas.

3 Provisional data.

Source: Department for Education 
66.7 per cent of pupils achieving five or more GCSE passes at grades $A^{*}$ to $C$ that include English and Mathematics; Portsmouth had the lowest percentage at 42.3 per cent in 2009/10, 12.6 percentage points below the average for England (Figure 11).

In line with three other regions, the South East has 1 per cent of pupils who did not obtain any GCSE passes. Portsmouth had the highest proportion within the South East at 2.5 per cent of pupils at Key Stage 4 who achieved no graded GSCE passes in 2009/10, whereas Windsor and Maidenhead had only 0.2 per cent of pupils with no graded GCSE results equal to the best education authority in England - Rutland.

Of those pupils who remain at school to study 'A' levels in the South East, on average 94 per cent achieved two or more passes in 2009/10, slightly above the average for England. In Wokingham the percentage was 99 per cent.

The proportions of 16- and 17-year-olds in post-compulsory education or government supported training schemes in the South East were 91 per cent and 79 per cent respectively in 2008, similar proportions to England.

In 2009, 33 per cent of those aged 16 to 64 in the South East were qualified to level 4 or higher of the National Qualification Framework (NQF). This was the second highest percentage (after London at 40 per cent) and above the average of 30 per cent for the UK as a whole. Conversely,

\section{Figure 12 Percentage of 16 to 64 -year-olds with NQF level 4 or above}

Local authorities in the South East with the 6 highest and 6 lowest percentages, 2009

Percentage points difference from UK average

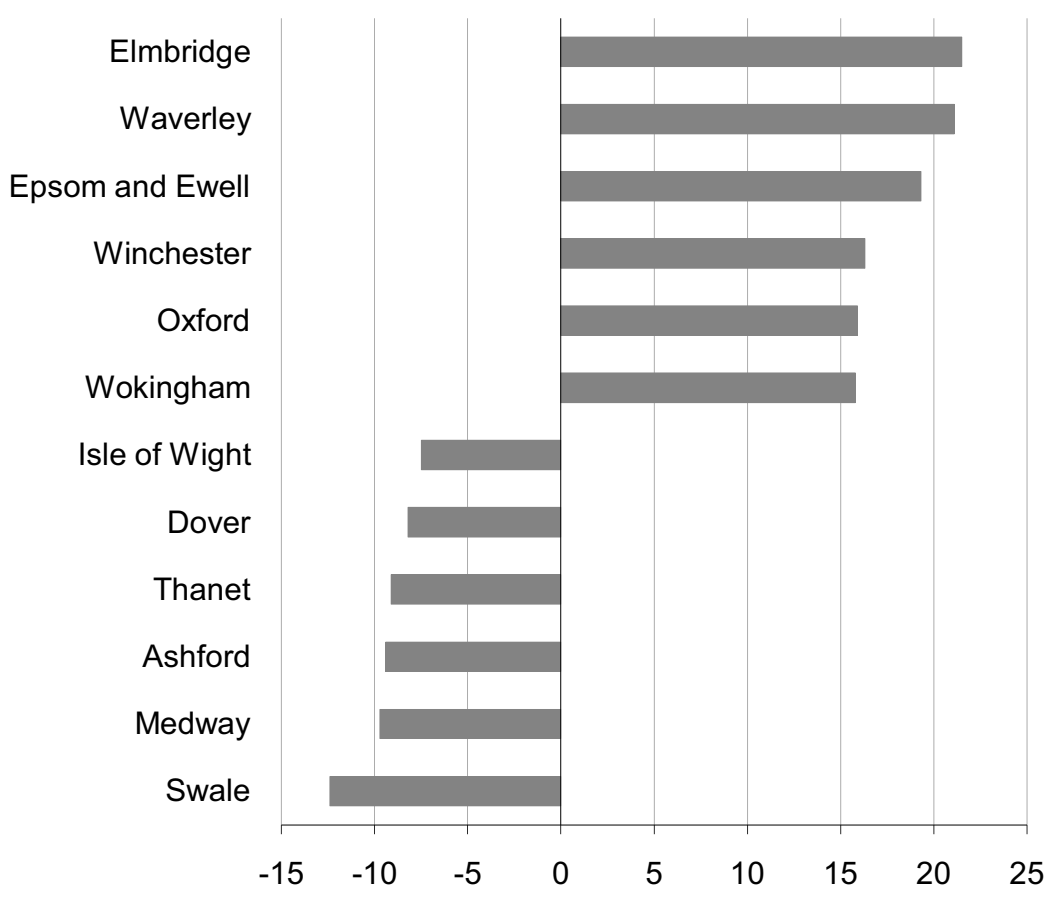

Note: UK average $=29.8$ per cent.

Source: Office for National Statistics 
the proportion of people aged 16 to 64 with no qualifications was 9 per cent, well below the average for the UK of 13 per cent.

There is wide regional variation with less than one in five of the working-age population having qualifications at NQF level 4 or above in Swale (Kent) (17 per cent) increasing to more than half of the working-age population in Elmbridge (51 per cent). Figure 12 shows the six districts with the highest and lowest percentages in the South East compared with the UK average.

In each of the five areas in the South East with the lowest proportions of adults qualified to NQF level 4 or above, the rate of people claiming work-related benefits (JSA) was about or above the regional average. Conversely, the areas with the highest proportions of residents qualified to this level had claimant count rates below the regional average. Residents in these latter areas also tend to have higher earnings.

\section{Labour market}

More than 4 million people resident in the South East were in employment in 2009. This represents 75.0 per cent of the population aged 16 to 64, the highest employment rate of any region or country of the UK. Employment rates in all regions have declined slightly during the last four years reflecting the recent recession as well as relaxation in retirement age legislation, increasing the pool of people available for work. Despite the current difficult economic climate the employment rate in the South East remained 4 percentage points above the UK average of 70.6 per cent in 2009. Conversely, the South East had the lowest regional unemployment rate of 5.9 per cent for people aged 16 and over, compared with a UK average of 7.6 per cent.

Within the South East, employment rates ranged from 65.2 per cent of the population aged 16 to 64 on the Isle of Wight to 85.9 per cent in Rushmoor in the north east of Hampshire. Although only seven districts in the region had employment rates less than the UK average, these were all located in coastal areas.

Of those people in employment, the South East had the joint highest percentage (with London) of those who were managers or senior officials, 18 per cent in 2009. Almost half of all employed people in the South East (48 per cent) were in managerial, professional and technical occupations (Standard Occupational Classification groups 1 to 3 ); this was the second highest percentage (after London at 54 per cent). These more advanced occupations accounted for more than twothirds (67 per cent) of those employed in South Bucks. At the other end of the scale, less than a third (32 per cent) of employed people in Thanet (Kent) were in groups 1 to 3. Of the 10 districts within the South East with the lowest proportions of employed people in advanced occupations, nine were coastal districts and the other was Crawley, fifth lowest with 36 per cent. A high proportion of employment in Crawley centres on Gatwick Airport and surrounding logistics activity, with many jobs in support services and less skilled occupations.

The South East had the second lowest proportion of those in employment engaged in elementary occupations, 10 per cent. This ranged from 5 per cent in the districts of Elmbridge and Woking (both in Surrey) to 21 per cent in Crawley (West Sussex). Figure 13 shows a selection of districts, one from each county, plus the unitary authority of Milton Keynes, as an example of the diversity within the region. 


\section{Figure 13a Percentage of workforce in managerial and professional occupations}

Selection of local authorities ${ }^{1}$ in the South East, 2009

Percentages

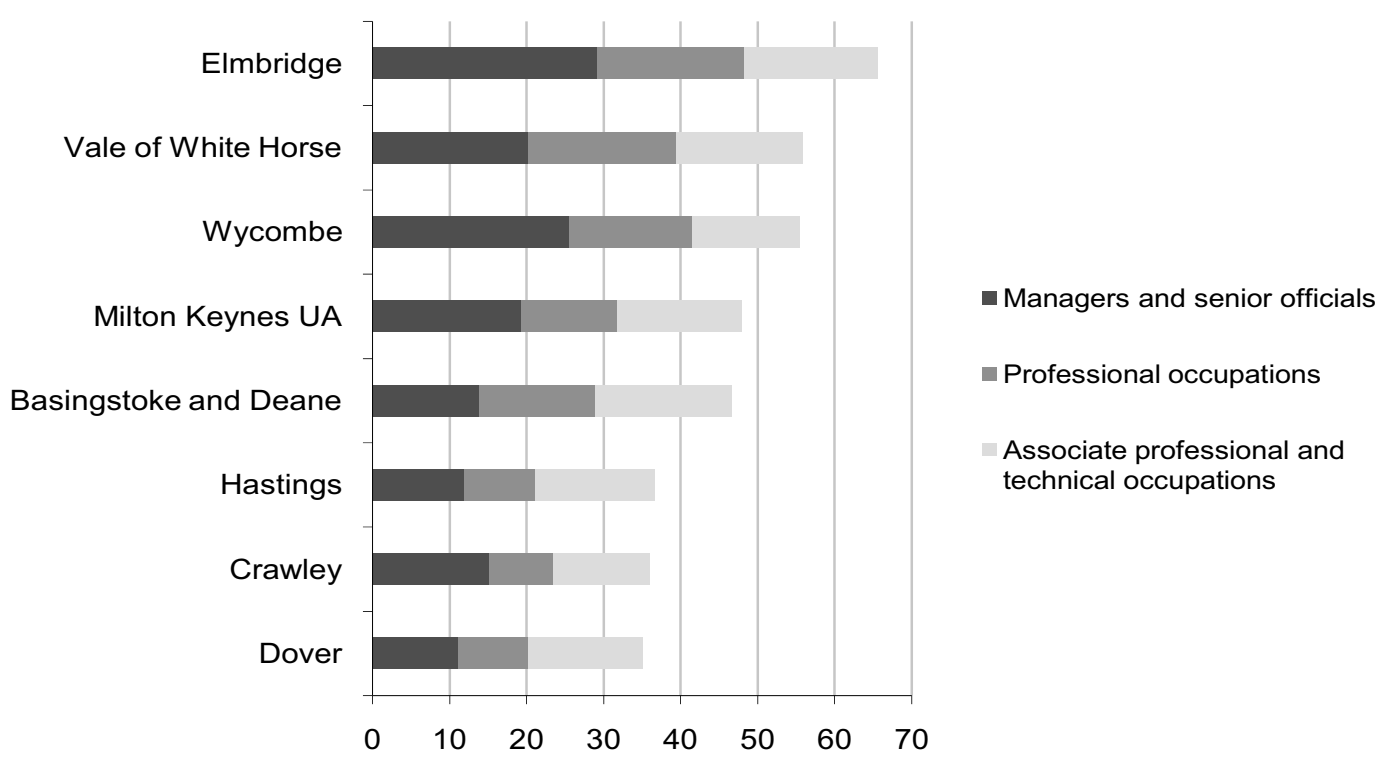

\section{Figure 13b Percentage of workforce in elementary occupations}

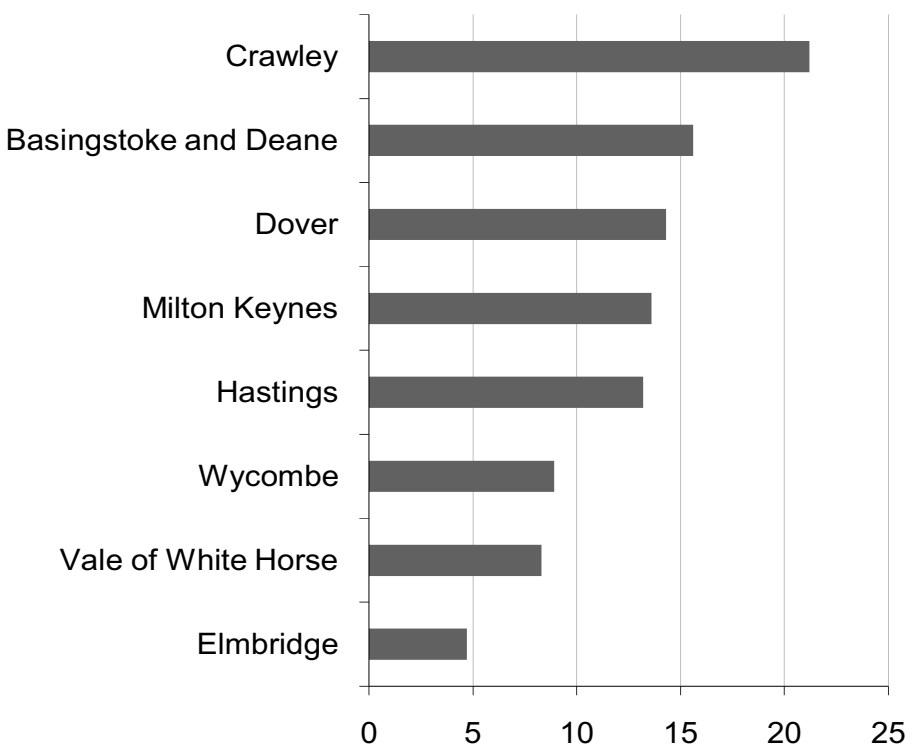

1 One selected from each county.

Source: Annual Population Survey, Office for National Statistics

Self-employment rates in the South East were among the highest in the UK at 10.4 per cent of the population aged 16 to 64 in 2009, compared with a UK average of 9.0 per cent. They ranged from 4 per cent in Gosport (Hampshire) to 22 per cent in Rother (East Sussex). Almost two-thirds of the 
districts and unitary authorities in the South East had rates of self-employment above the national average.

For local areas, unemployment rates are modelled to provide greater precision than estimates from surveys. Within the South East, unemployment was lowest in Hart (Hampshire) at 3.9 per cent in 2009 and highest in Medway at 9.4 per cent. Again coastal areas were worst affected, accounting for all but three of the districts with rates above the UK average of 7.6 per cent. The three noncoastal districts with high unemployment rates were Crawley, Slough and Milton Keynes with 7.9, 8.3 and 8.5 per cent respectively.

Jobseeker's Allowance provides an up-to-date indicator of unemployment at a local level. The proportion of residents in the South East who claimed Jobseeker's Allowance (JSA) was 2.4 per cent of the population aged 16 to 64 in August 2010, the lowest percentage jointly with the South West of any region or country of the UK. This was a reduction of 0.5 percentage points since the peak of 2.9 per cent in August 2009, but remained above the pre-recession average for the region. In terms of total numbers, 90,600 males and 41,600 females were claiming JSA in August 2010, increases of 55 per cent and 82 per cent respectively between August 2006 and August 2010.

\section{Figure 14a Median gross weekly earnings for full-time employees: by county and unitary authority, workplace based}

South East, April 2009

$£$ per week difference from UK average

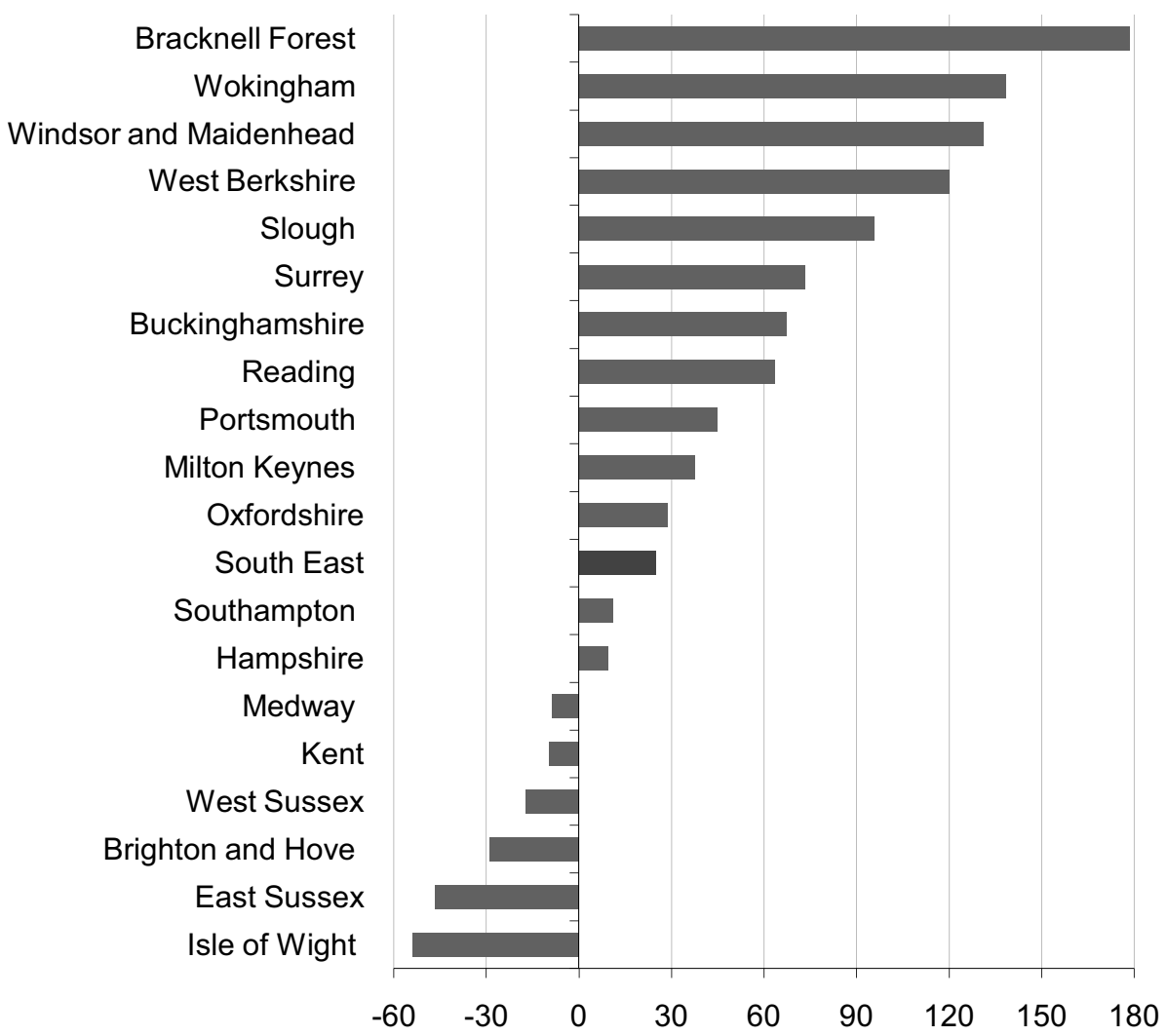

Note: UK average $=£ 488.70$ per week

Source: Annual Survey of Hours and Earnings, Office for National Statistics 
According to the Annual Survey of Hours and Earnings (ASHE) the median gross weekly earnings for full-time workers employed in the South East were $£ 514$ per week in April 2009, compared with an average of $£ 489$ for the UK and second only to London with $£ 627$ per week. Within the region there were wide disparities in earnings with employees in Thanet (Kent) earning only slightly more than half those in Mole Valley (Surrey), $£ 374$ compared with $£ 699$ per week for the latter. Figure 14a shows the range of earnings for the counties and unitary authorities within the South East of those adults working full-time in April 2009.

More than 410,000 people resident in the South East travel into London to work each day, equivalent to 9.9 per cent of the workforce. Conversely, around 13 per cent of the South East workforce travel from other regions to work. In addition to these, many people travel within the region to centres of business on a daily basis, some covering considerable distances.

\section{Figure 14b Difference between workplace- and residence-based earnings ${ }^{1}$ : by county and unitary authority}

South East, April 2009

$£$ per week difference (workplace minus residence)

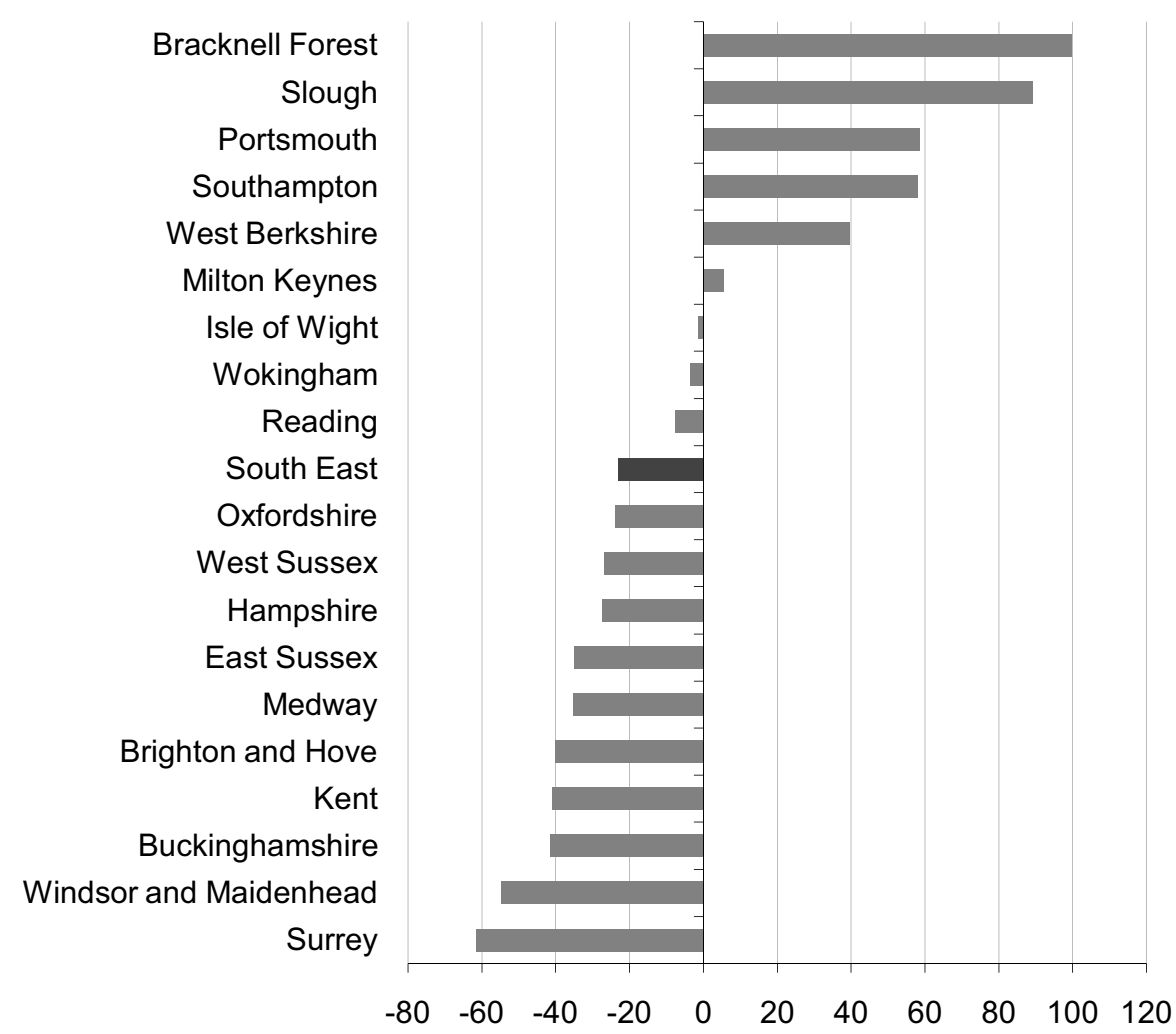

Note: UK average $=£ 488.70$

1 Median gross weekly earnings of full-time employees.

Source: Office for National Statistics

Earnings are also estimated on the basis of where people live and patterns can be different, indicating which locations may be employment hubs. Median earnings for residents in the South East were on average more than $£ 20$ per week higher than workplace based estimates. This 
reflects the fact that some residents, for example in Surrey, Buckinghamshire, and Windsor and Maidenhead, earn higher wages elsewhere (Figure 14b). Other areas such as Slough and Bracknell Forest are centres of employment attracting employees from other locations, with average workplace earnings above that of the resident population.

Within the South East median earnings were lowest for residents of Hastings (in East Sussex) at $£ 386$ per week, followed by Adur (West Sussex) £404 and Thanet (Kent) at £423 per week. Residents of Elmbridge (Surrey) earned the most at $£ 708$ per week, with Chiltern (in Buckinghamshire) and Windsor and Maidenhead residents earning $£ 680$ and $£ 675$ respectively each week. In Mole Valley (Surrey) residents earned an average of $£ 575$ per week, $£ 120$ per week less than people who worked in the district, reflecting the fact that several high profile companies have major offices in the area attracting workers from outside.

\section{Economy and business}

The economy of the South East as measured by gross value added (GVA) was worth $£ 176.5$ billion in 2009, which was the second highest of any region (after London) and constituted more than 14 per cent of the UK total. The value of GVA in the South East decreased between 2008 and 2009 by 2.7 per cent, compared with an average decrease of 2.1 per cent for the UK as a whole. Within the South East, Surrey contributed the highest proportion of GVA, 15 per cent of the regional total in 2008. However, GVA is a function of the size of an area and how many people are producing goods and services and earning wages, therefore GVA per head is often used to facilitate comparison between areas. Per head values reflect economic activity on a workplace basis relative to the population who are resident there and the impact of commuting is greater in some areas than others. More appropriate measures of productivity are GVA per hour worked or per filled job see Box 2 for further details: it is advisable to use these measures when comparing sub-regions.

\section{Box 2 Measuring Regional Economic Performance}

When measuring the economic performance of regions or sub-regions, the following should be considered:

Gross Value Added (GVA) is a good measure of the economic output of a region.

GVA per head, which divides output of those working in a region by everybody living in the region, should not be used as an indicator of either regional productivity or income of residents.

GVA per hour worked and GVA per filled job are the preferred measures of productivity of an area.

Gross Disposable Household Income (GDHI) per head is a good indicator of the welfare of residents living in a region. GDHI is the amount of money households have available for spending or saving.

Productivity, Income and Labour Market indicators should be used together to provide a more complete picture of regional and sub-regional economic performance.

For further information, see the National Statistician's article 'Measuring regional economic performance' which can be found at

www.statistics.gov.uk/cci/article.asp? ID $=2103$

and the Regional Economic Indicators articles published in Economic and Labour Market Review, for example

www.statistics.gov.uk/elmr/02 10/downloads/ELMR Feb10 Knight.pdf 
GVA per head was almost $£ 21,000$ for the South East in 2009 , the second highest (after London with $£ 34,000)$. This gap was narrower on a residence basis $(£ 22,500$ compared with $£ 31,000)$ indicating that some South East residents earn higher salaries elsewhere. In the six unitary authorities of Berkshire GVA per head was similar to some areas of London at almost $£ 32,000$ in 2008, whereas in the Isle of Wight, Medway and East Sussex the figures were less than half this at $£ 12,500, £ 13,000$ and $£ 14,000$ respectively.

In 2008, 29 per cent of the $£ 181.4$ billion GVA in the South East was attributable to the real estate, renting and business services sector; this represented a 6 percentage point increase in proportion since 1995. Conversely, the proportion of GVA earned from manufacturing reduced by around 8 percentage points. There were small changes in other sectors with construction and other services each taking a larger share of the total compared with 1995. The wholesaling and retailing sector was the second largest sector in the South East contributing 13 per cent of total GVA in 2008.

Using one of the preferred measures, GVA per filled job has a narrower range of values for the Nomenclature of Units for Territorial Statistics level 3 (NUTS 3) areas than for GVA per head. For example, GVA per filled job was lowest in the Isle of Wight, 22 per cent below the UK average, compared with 37 per cent below the UK average on a GVA per head measure in 2007.

\section{Figure 15 Gross value added per filled job relative to UK: by NUTS $2^{1}$ and NUTS $3^{1}$ areas}

South East, 2007

Index, UK $=100$

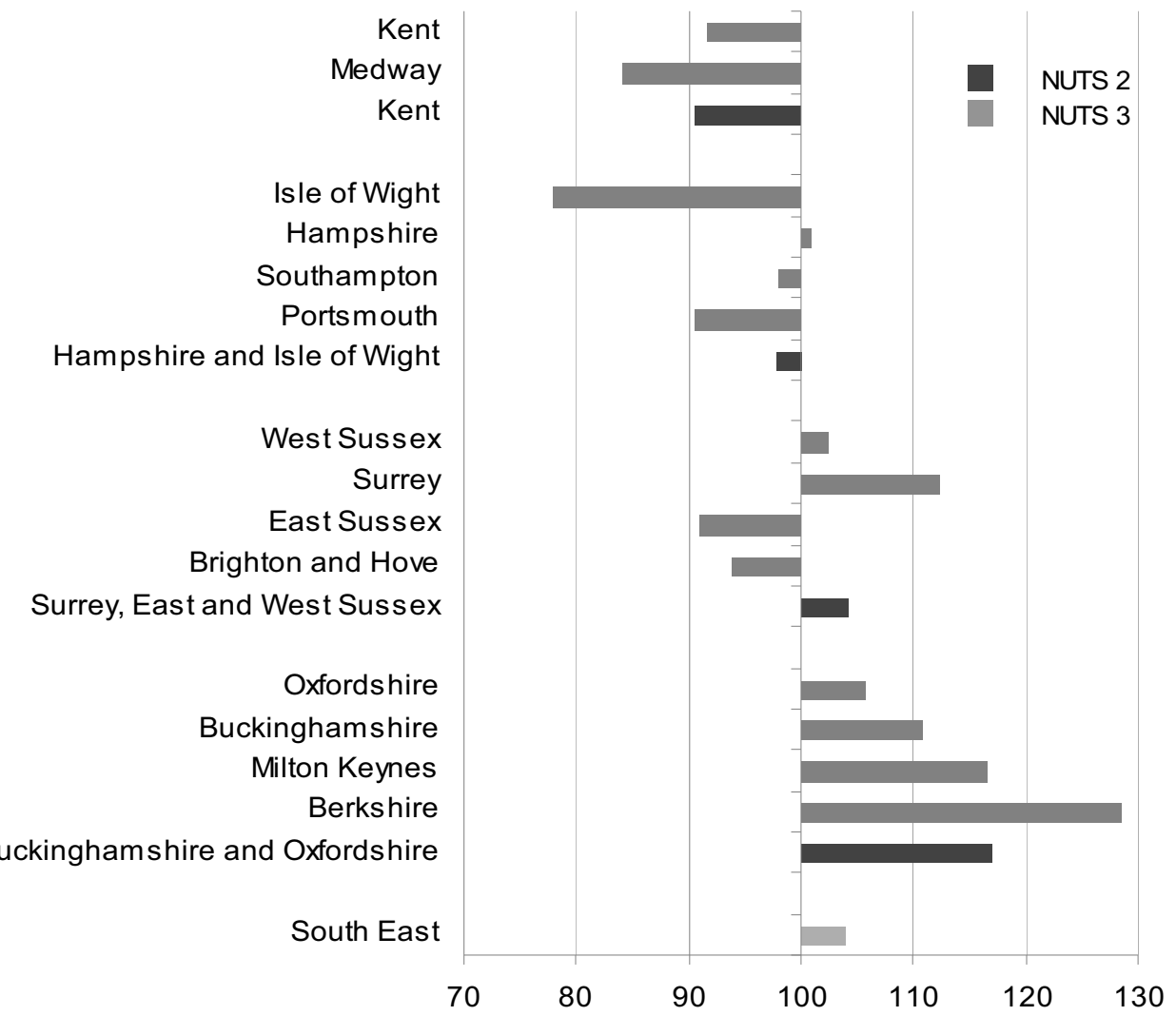

1 Nomenclature of Units for Territorial Statistics (NUTS) levels 2 and 3.

Source: Office for National Statistics 
Productivity per filled job across the whole of the South East was 4 per cent above the average for the UK in 2007. Berkshire had the highest productivity in the South East, 29 per cent above the national average. On the GVA per head measure, Berkshire was nearly twice this percentage above the national average with an index of 156.1 (UK=100). Figure 15 shows GVA per filled job for the NUTS 3 areas of the South East relative to the UK average, with averages for their NUTS 2 areas in darker blue. Further analysis of these measures and the factors contributing to productivity can be found in Economic and Labour Market Review (February 2010) (see Box 2).

Locally identified priorities for the South East have designated six sectors of key importance for the area which revolve around high value, advanced technological industries with innovative potential. In the Thames Valley and along the M4 corridor there are large numbers of businesses focussing on information and communications technology (ICT) and digital media; there are also centres for aerospace and defence research, as well as pharmaceutical development and healthcare. Whether individual businesses relate to high performance cars, train maintenance or small specialist boat builders, advanced engineering is critical to the region. Approximately a third of the business units in the South East relate to these priority sectors, producing almost half the total turnover. Throughout the South East, professional services and support industries are vitally important and many have located themselves here, within easy reach of companies in the capital and other major cities, but taking advantage of lower costs.

\section{Figure 16 Employee jobs: by industry for NUTS $2^{1}$ areas}

South East, 2008

Percentages

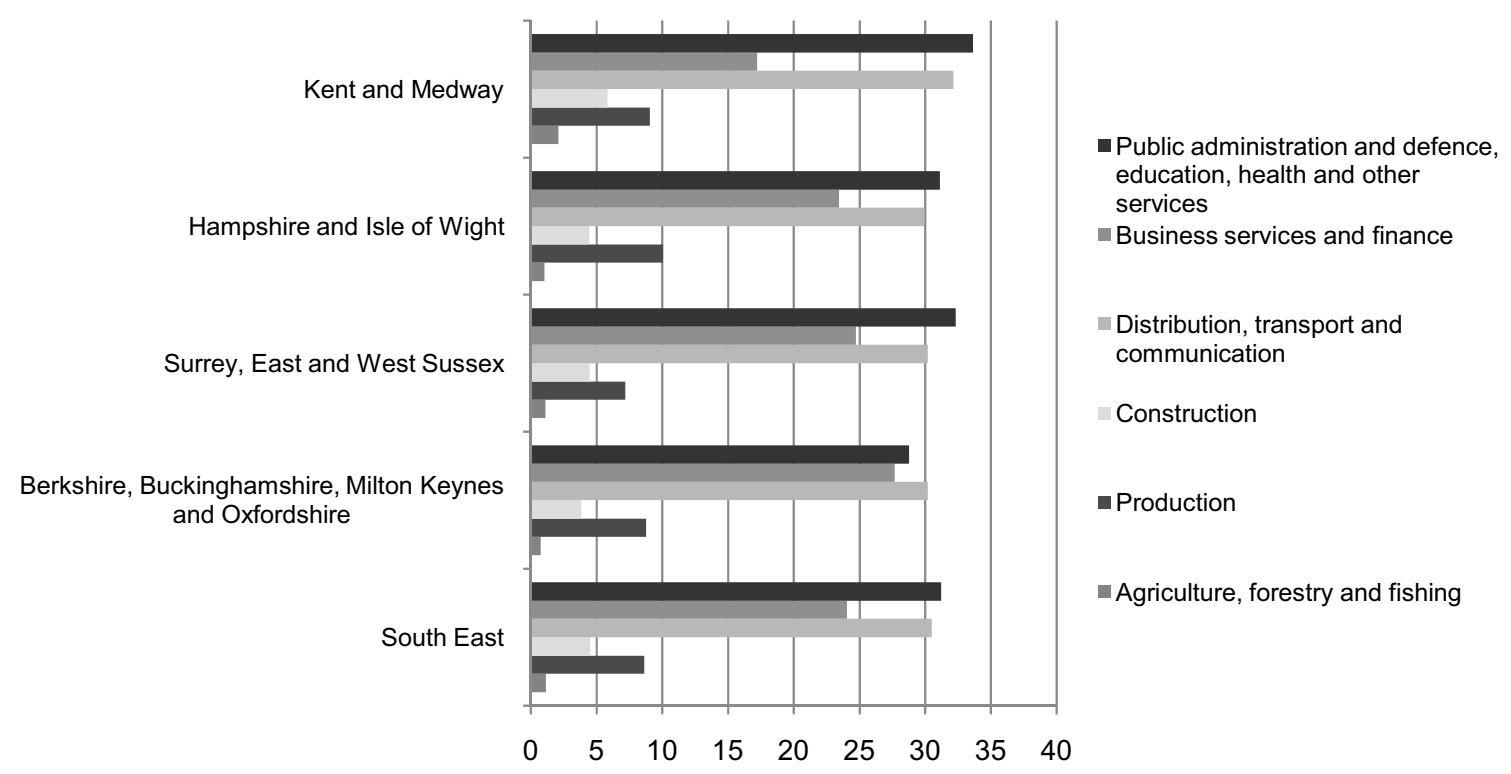

1 Nomenclature of Units for Territorial Statistics (NUTS) level 2.

Source: Annual Business Inquiry, Office for National Statistics

Around 30 per cent of the workforce were engaged in the distribution, transport, wholesale, retail and communications sector in 2008 , with a slightly higher proportion engaged in public administration, defence, health, education and other services. This latter sector covers people who work for private organisations as well as those who are in the public sector. The next largest sector 
in the South East is business services, professional, scientific, technical support and finance which accounted for about a quarter of the workforce.

An industrial breakdown of employee jobs (Figure 16) illustrates some differences for NUTS 2 areas within the South East, which may also provide further evidence of why some areas have productivity gaps compared with the region as a whole. One of most obvious differences is in the business services and finance sector: across the South East 24 per cent of employee jobs were in this sector in 2008, however in Kent and Medway the proportion was 17 per cent. The lower level of employment in business services and finance coupled with lower than average productivity in this NUTS 2 area could help explain some of the relative productivity gap. In areas such as Berkshire, Buckinghamshire and Oxfordshire, employment above the regional average in sectors with high productivity, such as business services, boosts the area's GVA. Kent has a higher proportion of employment in distribution, transport and communications than the rest of the region (32 per cent compared with 30 per cent regionally), partly reflecting the presence of several major ports and the Channel Tunnel rail link. There is also above average employment in agriculture, forestry and fishing which are relatively low value added industries.

In March 2010 there were 330,000 businesses in the South East registered for VAT and/or PAYE. There are additionally a similar number of businesses who will not be registered for either as they fall below the thresholds for these systems. The registered businesses equate to an average of 483 per 10,000 adults in the South East. For further details see Annex.

\section{Figure 17 Expenditure on research and development: by region UK, 2008 \\ $£$ billion}

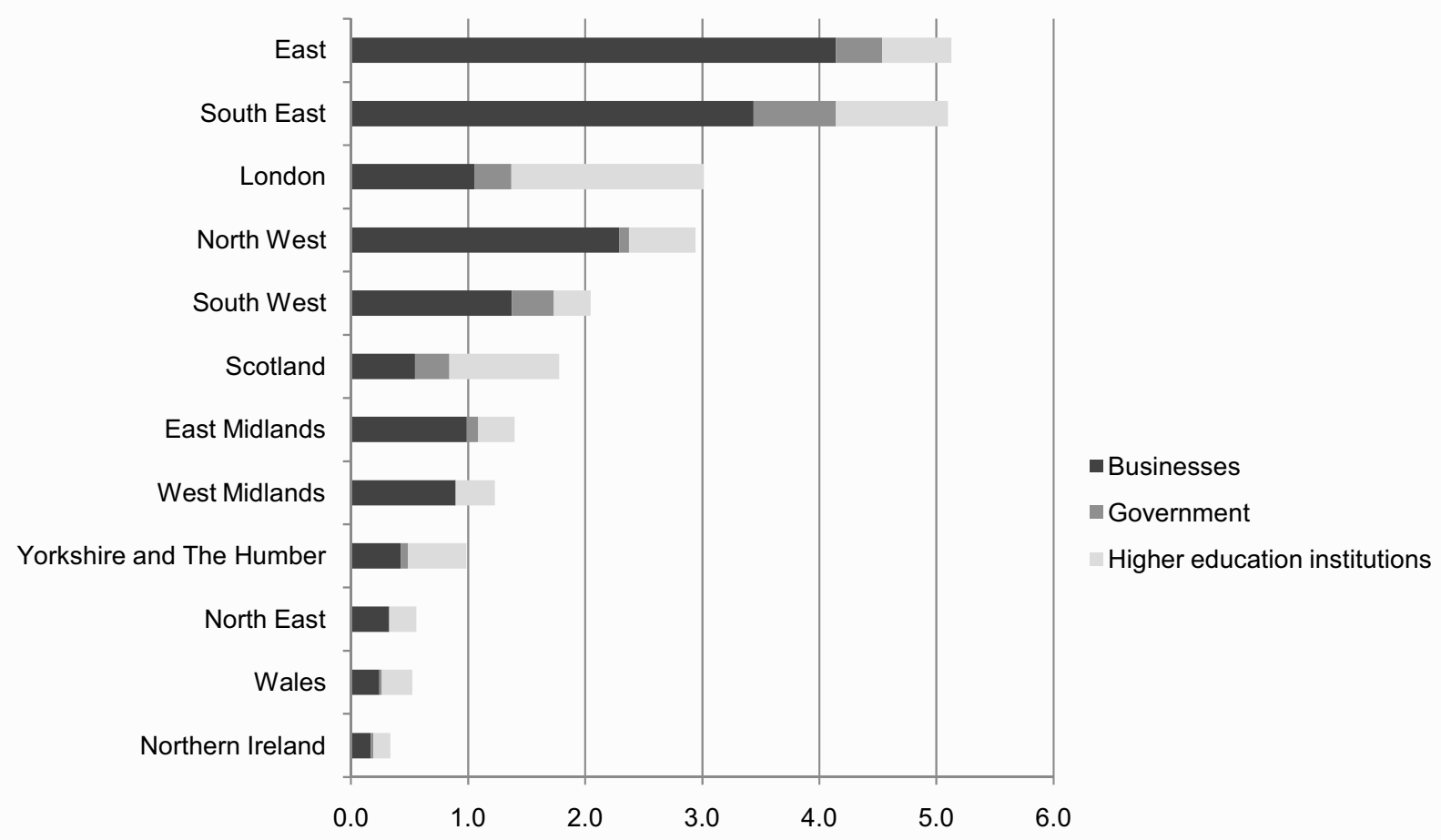

Source: Office for National Statistics 
Expenditure on research and development (R\&D) is an indicator of innovation and where entrepreneurial activity may be higher. In 2008 more that $£ 5$ billion was spent on R\&D in the South East, only slightly less than in the East of England. Each of these two areas accounts for more than one-fifth of the UK total. Business enterprises alone spent almost £3.5 billion, 67.5 per cent of the South East total, which was 4 percentage points more than the average for the UK. In addition, government spent $£ 700$ million on R\&D projects in the South East, the highest amount of any region (Figure 17).

In the South East, gross disposable household income (GDHI) per head was $£ 16,800$ in 2008, 13 per cent above the national average of $£ 14,900$. Within the South East, GDHI was highest in Surrey at $£ 21,000$ per head and lowest in Portsmouth at $£ 11,100$ per head, 74.6 per cent (threequarters) of the of UK average. Medway, Isle of Wight and Southampton also had GDHI per head below the national average and Milton Keynes and Brighton and Hove were only two to three per cent above the UK average.

\section{Disadvantage}

According to the 2007 Index of Multiple Deprivation (IMD 2007), just 318 (6 per cent) of the South East's Lower Layer Super Output Areas (LSOAs) were in the most deprived quintile (fifth - see Box 3) nationally, the lowest proportion of any region in England. Conversely, nearly 38 per cent were in the highest quintile (Figure 18). The whole of the South East accounts for 16 per cent of all LSOAs in England but it accounted for just under 5 per cent of the most deprived fifth nationally; more than 31 per cent of LSOAs in the region were in the least deprived fifth.

\section{Box 3 Index of Multiple Deprivation 2007}

The Index of Multiple Deprivation (IMD) provides a summary measure of relative deprivation at Lower Layer Super Output Area (LSOA) level in England. The IMD aims to provide a nationally consistent measure of how deprived an area is by identifying the degree to which people are disadvantaged by factors such as low income, unemployment, lack of education, poor health, and crime. Particular points to note:

- Not all deprived people live in deprived areas and conversely, not everyone living in a deprived area is deprived; the indicators identify areas with characteristics associated with deprivation not deprived people.

- The indices should not be used as a measure of affluence. A lack of income deprivation does not necessarily equate to affluence;

The indices provide a relative measure of deprivation and therefore cannot be used to determine how much more deprived one LSOA is than another.

This article uses the rankings of all LSOAs in England, which have been divided into five equal sized groups, or quintiles. In England 20 per cent of LSOAs are in the most deprived quintile and 20 per cent in the least deprived quintile and so on. If an area (region or local authority) had the average distribution of deprivation they would have 20 per cent of LSOAs in each quintile.

For more information on the IMD see the Neighbourhood Statistics website: www.neighbourhood.statistics.gov.uk 


\section{Figure 18 Distribution of LSOA ${ }^{1}$ rankings on the 2007 Index of Multiple Deprivation: by county and unitary authority}

South East, 2007

Percentages

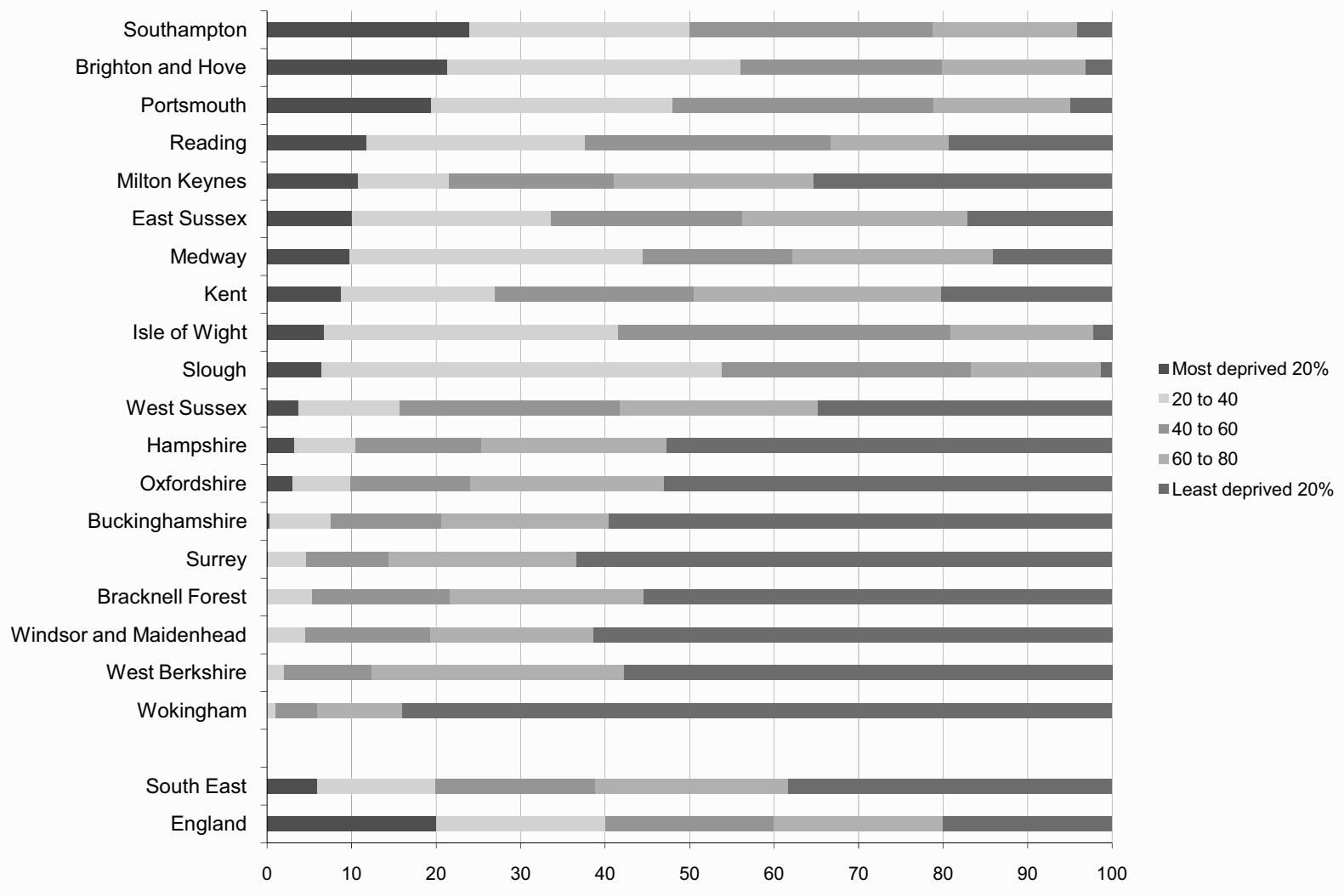

1 Lower Layer Super Output Areas.

Source: Communities and Local Government

In 8 of the 19 counties and unitary authorities in the region more than 50 per cent of LSOAs were in the least deprived quintile, however substantial pockets of deprivation do exist. Southampton, Brighton and Hove, and Portsmouth had a higher or similar proportion of LSOAs in the bottom quintile than the national average (24, 21 and 20 per cent respectively). The least deprived upper tier local authority in the region was Wokingham, where 84 per cent of LSOAs were in the least deprived quintile.

The South East had the second lowest proportion of workless households (12.6 per cent), after the East of England (12.2 per cent). Of the 2.4 million working-age households in the region in 2008, 304,000 were workless and 645,000 contained both working and non-working adults. Just under 12 per cent of children in the region lived in workless households, more than 5 percentage points fewer than the average across Great Britain (17 per cent).

Figure 19 shows the proportion of workless households in each county and unitary authority of the South East. The proportion of workless households ranged from about 6 per cent in Windsor and Maidenhead and West Berkshire to 18 per cent in Brighton and Hove and 19 per cent on the Isle of Wight. 


\section{Figure 19 Workless households ${ }^{1}$ : by county and unitary authority}

South East, 2008

Percentage of all households

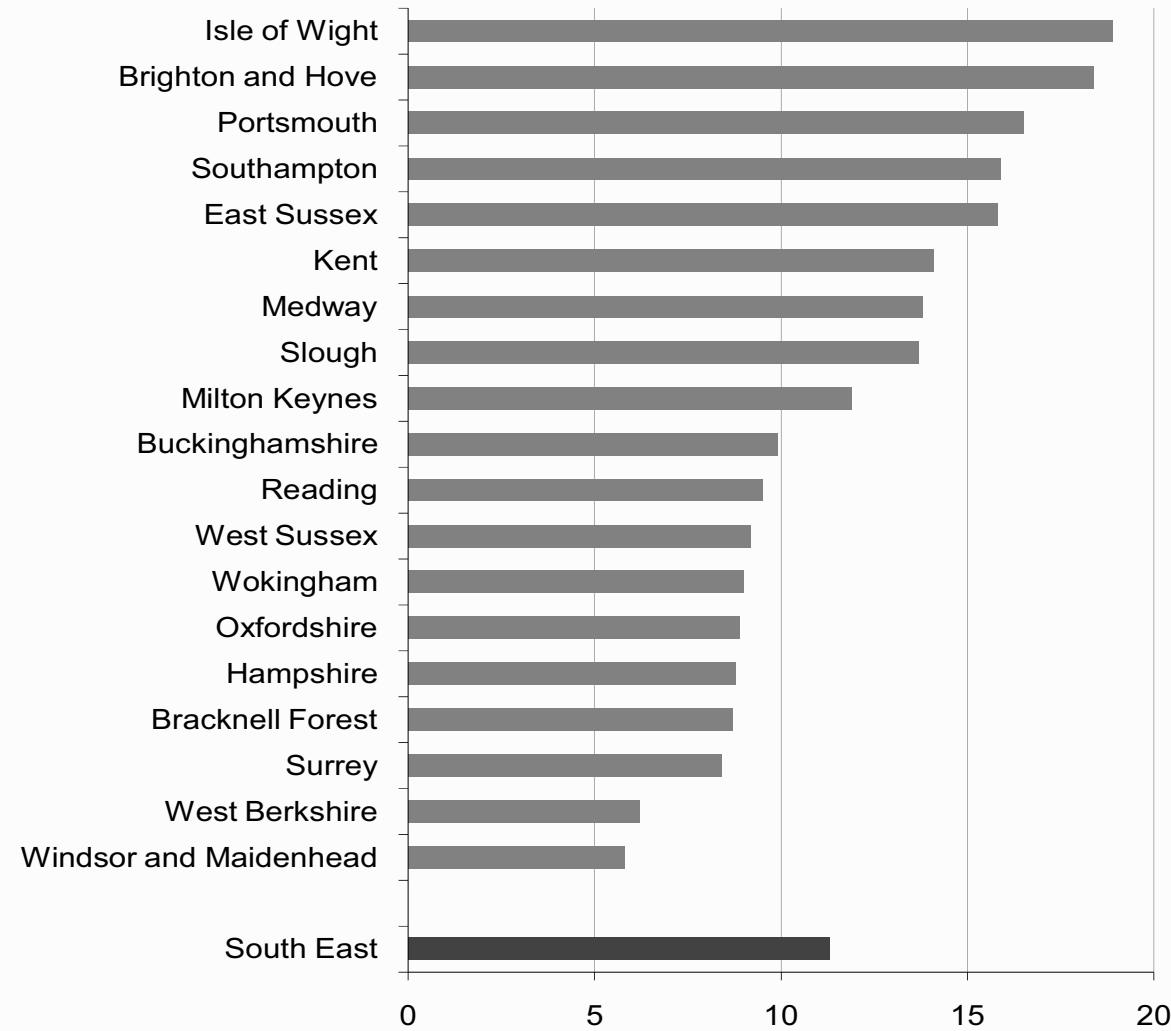

1 A workless household is one which contains at least one person aged 16 to 64 where no-one aged 16 or over is in employment.

Source: Annual Population Survey, Office for National Statistics

\section{Health}

Life expectancy at birth for both males and females in the South East are above the national average (Figure 20). In 2007-2009 male life expectancy was the highest of any UK region (79.4 years) while female life expectancy was similar to the South West (83.3 years each). Within the region life expectancy at birth for males ranged from 76.5 years in Thanet (Kent) to 81.8 years in Epsom and Ewell (Surrey). For females the range was 80.8 years in Hastings (East Sussex) to 85.6 years in Hart (Hampshire).

The region had the joint lowest infant mortality rate of 4 per 1,000 live births in 2008 and a lower proportion of babies weighed less than $2.5 \mathrm{~kg}$ at birth than in any region apart from the South West (6.3 and 6.2 per cent respectively). Between 2005 and 2008 the proportion of births less than 2.5 $\mathrm{kg}$ decreased from 6.9 to 6.3 per cent, compared with a reduction across England as a whole from 7.5 to 7.2 per cent. Within the South East the proportion of live births less than $2.5 \mathrm{~kg}$ ranged from 4.2 per cent in Shepway (Kent) to a high of 8.7 per cent in Slough.

The South East had a standardised mortality ratio $(S M R)$ of 90 , the lowest in the UK $(S M R=100)$ in 2008. The SMR is the ratio of observed deaths to those expected if UK age-specific death rates 


\section{Figure 20 Life expectancy at birth: by region and country}

UK, 2007-2009

Difference in years from the UK average

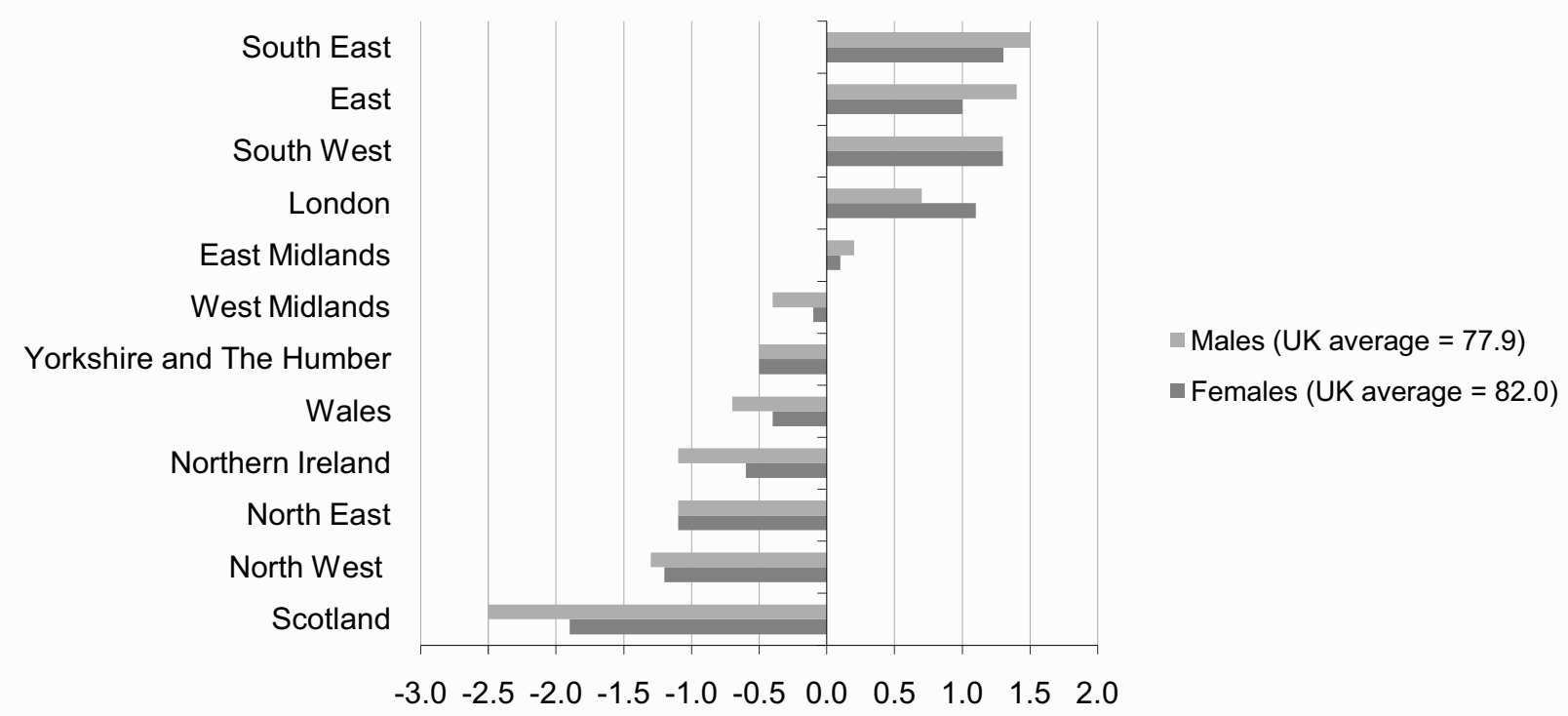

Source: Office for National Statistics

were applied to the population, so in the South East there were 90 actual deaths for every 100 expected deaths. Medway and Worthing (West Sussex) had the highest SMR in the region at 107 and 106 respectively, six other areas had SMRs higher than or equal to the national average: Thanet, Swale (Kent), Lewes, Dartford, Milton Keynes and Southampton. The lowest SMRs in the South East were in Hart and Epsom and Ewell (both 73), which were the lowest of any local authority in the UK with the exception of the Isles of Scilly, the City of London, Westminster and Kensington and Chelsea. While standardised mortality ratios take account of differences in the demographic composition of areas, they take no account of the uneven nature of healthcare infrastructure, for example that a single hospital may serve the residents of several local authorities.

\section{Transport}

Most locations in the South East are reasonably accessible, although the region is dominated by transport routes radiating into and out of London and travelling across the region is more difficult (Map 21). The high speed rail link to European cities passes through Kent and several major ports for freight and passengers are located along the coast, including Dover, Portsmouth and Southampton. The South East is home to Gatwick Airport, the second busiest airport in the country, handling 34 million passengers in 2008 , and the region borders Heathrow, one of the busiest airports in the world.

Dover alone handles 60 per cent of the UK's international sea passengers - 13.8 million in 2008; a further 2.1 million passengers used Portsmouth, the second busiest port in the country. More than 40 million tonnes of freight was shipped through Southampton in 2008, which represented 7 per 
cent of the UK total; another 43 million tonnes were conveyed through Dover, Medway and Portsmouth. Millions of containers and lorries use the South East ports and roads each year.

\section{Map 21 South East: regional transport network}

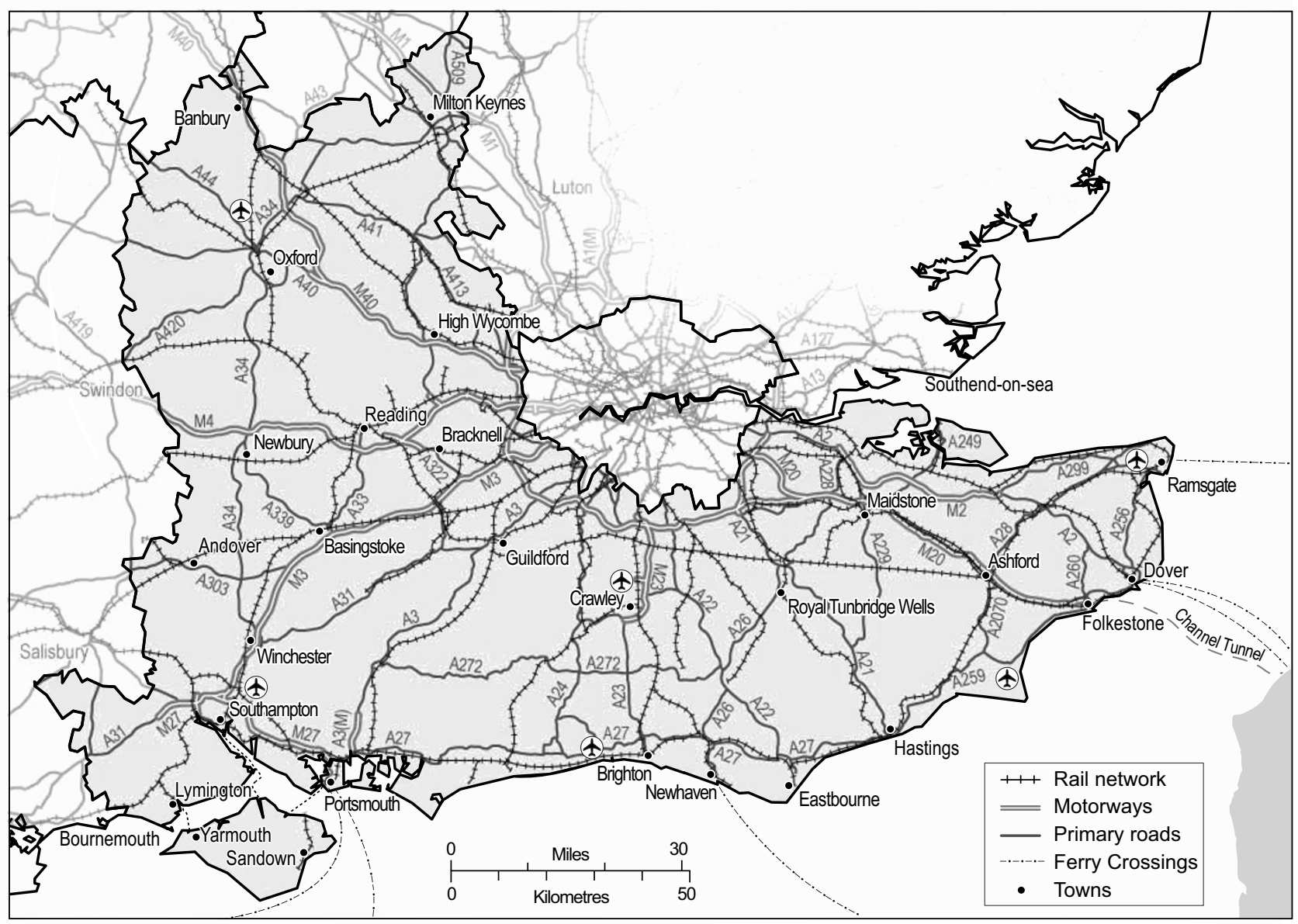

@ C Crown copyright and database right 2010. Ordnance Survey Licence100019153.

The South East had the highest rate of car ownership with 68 cars for every 100 people aged 17 or over. Only 17 per cent of households did not have access to a car, which was the joint lowest proportion with households in the South West. The South East had the highest motoring costs per household of any region or country of the UK, $£ 76.90$ per week $-£ 15$ more than the average for each household in 2007/08. Purchase and repair of vehicles was the main source of the additional expense.

Residents of the South East travelled an average of more than 8,100 miles during 2007 to 2008, the second greatest distance of any region (after those in the East of England). Four-fifths (81 per cent) of this distance travelled was by car, either as a driver or passenger and only 2.4 per cent of the total by local bus. Other forms of public transport accounted for a further 12 per cent of the distance travelled, of which trains were a major component.

Not surprisingly, given the South East's size, population and location, the region had by far the highest number of vehicles using its roads - travelling 87.1 billion vehicle kilometres in 2008, more than 50 per cent above the next busiest region, the North West. Inevitably with this high volume of 
traffic there were also more accidents reported, in excess of 25,000 during 2008. However, in relation to the vehicle kilometres travelled, the number of accidents was well below the national average at 289 compared with the average for Great Britain of 335 accidents per billion vehicle kilometres.

Average daily motor vehicle flows on both major and minor roads remained unchanged in the South East between 1998 and 2008 at 5,000 vehicle kilometres per day, although there were small increases in most other regions. However, the flows on motorways increased by 18 per cent from 79,000 to 94,000 thousand vehicle kilometres per day.

The proportion of 5- to 16-year-olds resident in the South East who walked to school during 2007 to 2008 was 38 per cent, the lowest of any region and 7 percentage points below the Great Britain average. This may be partly a result of above-average distances that many children travel to school: the average journey length for 5- to 10-year-olds was 1.9 miles, with the older group of 11 to 16 -year-olds travelling 3.3 miles each way.

Half of the passenger journeys in the South East have London as their destination, with people travelling there for work, leisure, shopping and cultural activities. In the South East 7 per cent of journeys to work were by rail, the third highest in the country, after London and the East of England at 12 and 8 per cent respectively.

By using information about the location of people's employment compared with their usual place of residence, a picture of commuting patterns can be built up. About 5 per cent of residents of Surrey and Kent work in central London, with around a further 10 per cent from each of these counties working in outer London boroughs. As you move away from the inner core of the South East these proportions decline and the numbers commuting to London from rural areas for example are negligible. However, where rail links are good, for example Brighton and Hove, a small proportion of residents travel longer distances to the city to work.

As well as being a key port for both passengers and freight, Dover is linked to the continent by means of the Channel Tunnel, moving passengers and vehicles by train. Around 1 million trucks carrying 1.2 million tonnes of freight use the tunnel each year with corresponding impact on roads in the South East. In addition, Eurostar transports approximately 9 million passengers annually. The high speed rail link through Ebbsfleet and Ashford helps open up wider markets for the region.

\section{Environment}

In 2008 the South East produced 64,000 kilotonnes of carbon dioxide $\left(\mathrm{CO}_{2}\right)$, the highest of any region or country in the UK. However, this mostly reflects the fact that the South East has the largest population and extensive road networks; in terms of emissions per resident the region had the joint second lowest emissions at 7.6 tonnes per resident (Figure 22). At district/unitary authority level there are some substantial variations in emissions levels. The highest emissions per resident were in Tonbridge and Malling (in Kent), South Bucks, and New Forest (14.2, 14.1 and 13.8 tonnes per resident respectively). In Tonbridge and New Forest this is due to higher emissions from industry and commerce: despite its predominantly rural character, New Forest has an oil refinery and oil-fired power station at Fawley. In South Bucks, road transport contributed more than half of the district's total $\mathrm{CO}_{2}$ emissions, reflecting the presence of long motorway 
stretches of the M25, M40 and M4. The lowest rates of emission were found in Gosport, Hastings, and Epsom and Ewell (4.6, 4.8 and 5.1 tonnes per resident respectively).

\section{Figure 22 Carbon dioxide emissions: by region and country}

UK, 2008

Tonnes per resident

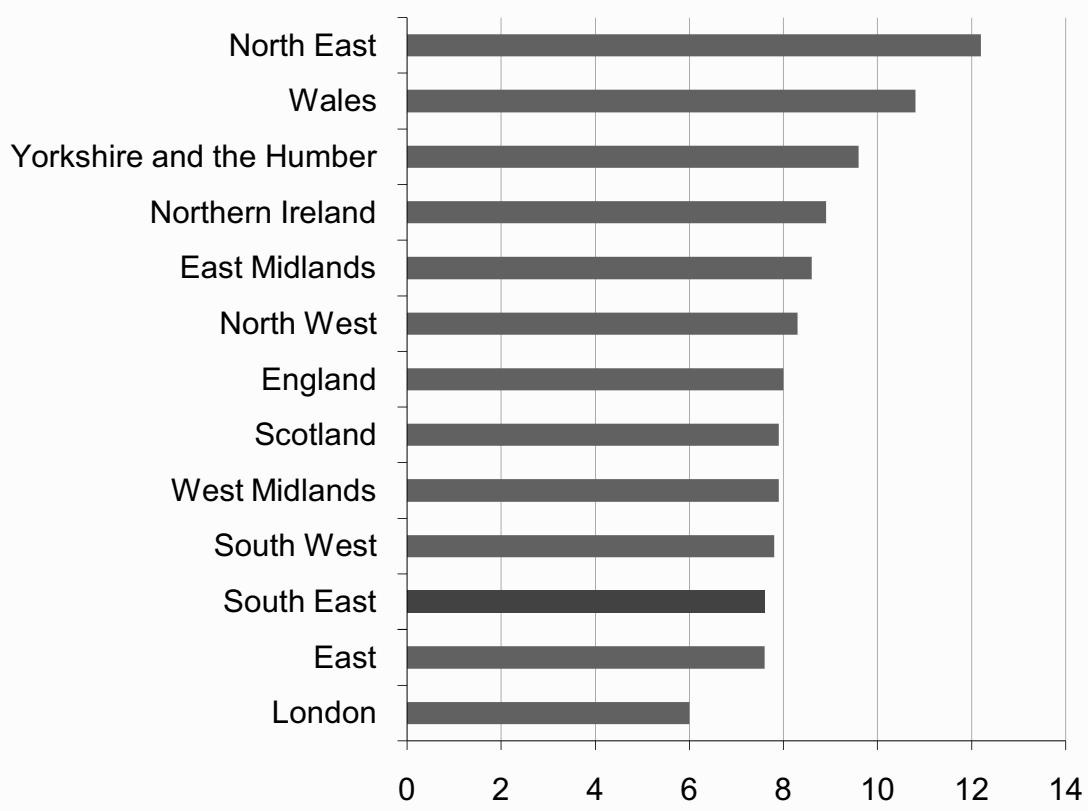

Note: England and Wales $=11.6$

Source: Department of Energy and Climate Change

A slightly higher proportion of household waste is sent for reuse, recycling or composting in the South East than in England as a whole (38.4 and 37.6 per cent respectively in 2008/09). Despite this, the region still produces more residual waste than average (683.5 compared with $668.8 \mathrm{~kg}$ per household). Local authorities in the region sent 46 per cent of municipal waste collected to landfill, the second lowest proportion of any region in the UK, after the West Midlands (33 per cent).

According to the Environment Agency, about 403,000 domestic and commercial properties in the South East are at risk of flooding; of these 31 per cent (nearly 125,000 properties) have a significant risk of flooding (defined as a 1 in 75 chance of flooding in a given year). Three local authorities in the region are in the top 10 nationally - both Windsor and Maidenhead and Runnymede are part of the Thames flood plain, while Shepway (Kent) is a coastal district famous for large swathes of marshland (such as Romney Marsh).

The Southern and Thames Environment Agency areas, which together cover the majority of the South East, have substantially less rainfall than the UK average of 1,200 millimetres ( $\mathrm{mm})$ in 2009, (840 $\mathrm{mm}$ for Southern and $730 \mathrm{~mm}$ for Thames).

A higher proportion of the South East's rivers were of good biological and chemical quality than England as a whole in $2008-75.8$ per cent in the case of biological quality, nearly 4 percentage points above the average. Eighty coastal bathing water areas in the Southern and Thames regions 
fall within the South East; in 2009 all of these were in compliance with European bathing water standards.

\section{Crime and justice}

Over all types of crime, the South East recorded 72 crimes per 1,000 population in 2009/10, the third lowest of any region (after the East of England and the North East). Violence against the person, criminal damage and general theft offences (excluding robbery and burglary) accounted for two-thirds of all offences recorded in many areas.

There is wide variation between locations and between different types of crime. Urban locations tend to have more crime than rural areas. Cities and business districts where there are high daytime populations relative to number of residents are understandably more vulnerable to crime and have higher rates. Deprivation also is a factor, and for example households in more deprived areas are three times more likely to be victims of burglary than those in the least deprived areas.

\section{Map 23 Recorded crime ${ }^{1}$ : by local or unitary authority ${ }^{2}, 2009 / 10$}

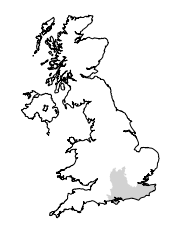

Recorded offences per 1,000 population

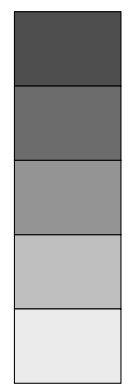

65.0 and over

45.0 to 64.9

35.0 to 44.9

25.0 to 34.9

24.9 or under

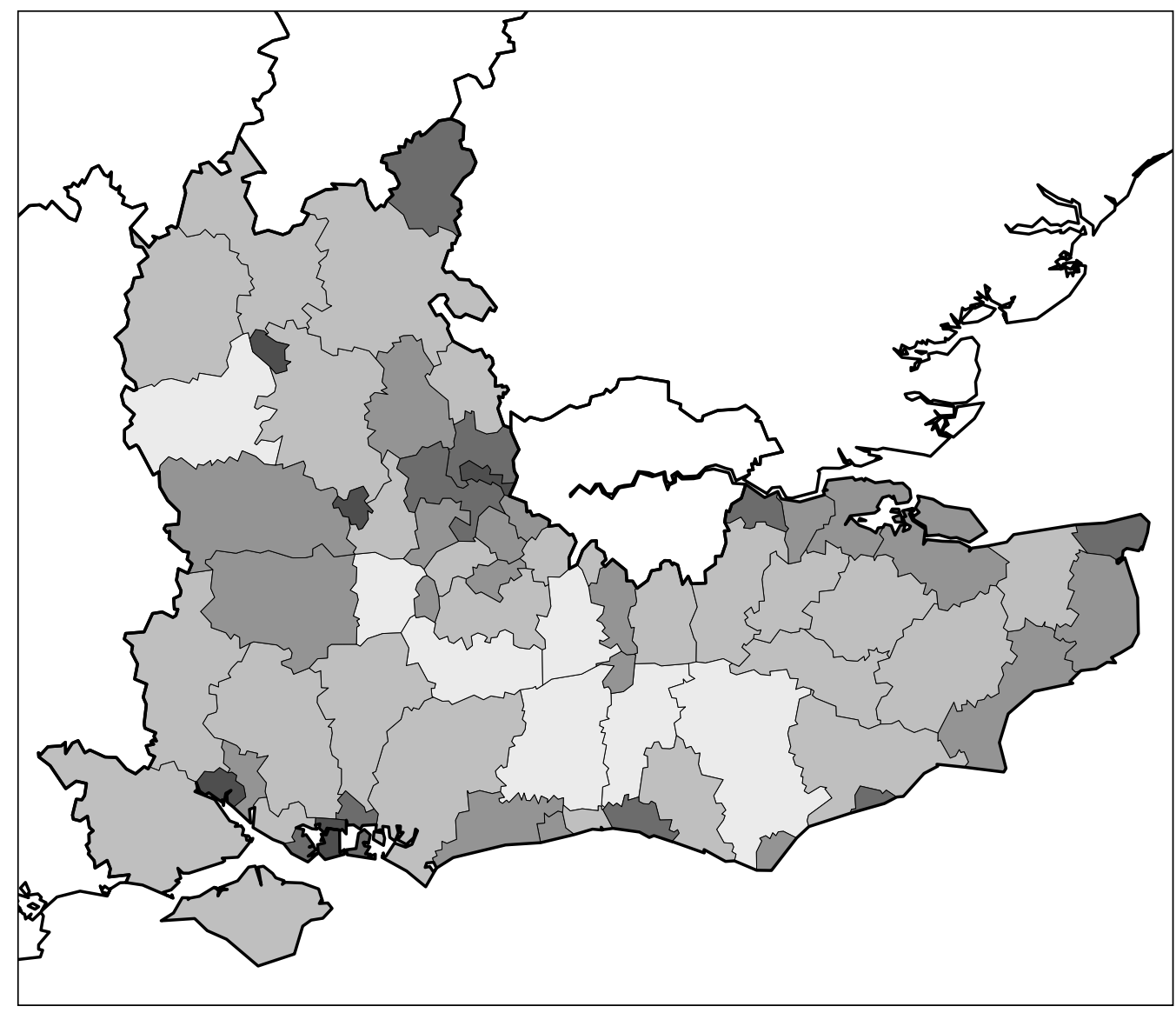

() Crown copyright and database right 2010. Ordnance Survey Licence 100019153

1 Selected crimes recorded by the police which relate to British Crime Survey (BCS) definitions and covers about 60 per cent of all recorded crimes. These
BCS comparator figures include the following crimes: theft of a vehicle, theft from a vehicle, vehicle interference and tampering, domestic burglary, theft of a
pedal cycle, theft from a person, criminal damage, common assault, wounding and robbery (of personal property not business property). 2 For key to local authorities see Map A3.

Source: Home Office 
For local authorities selected recorded crimes can be related to British Crime Survey (BCS) definitions, and composite comparators have been produced for each authority (Map 23). On this measure, Wealden in Sussex had the lowest rate of recorded crime within the South East at 19 incidents per 1,000 resident population, with Slough the highest with four times this rate (83 incidents per 1,000 population). For the South East, recorded crime for BCS comparators was 40 crimes per 1,000 residents compared with a rate of 45 for England and Wales in 2009/10.

As might be expected the rate of household burglaries was higher in urban areas, with Reading and Slough having rates of 18 and 13 offences per 1,000 households respectively above the national average in 2009/10. Only 10 local areas in the South East had rates greater than the average for England and Wales of 11.6 burglaries per 1,000 households. In addition to the six districts shown in Figure 24, West Berkshire, Portsmouth, Wycombe and Milton Keynes each had rates of just above the national average.

\section{Figure 24 Burglary offences}

Local authorities in the South East with the 6 highest and 6 lowest percentages, 2009/10

Difference in rate per 1,000 households from England and Wales average

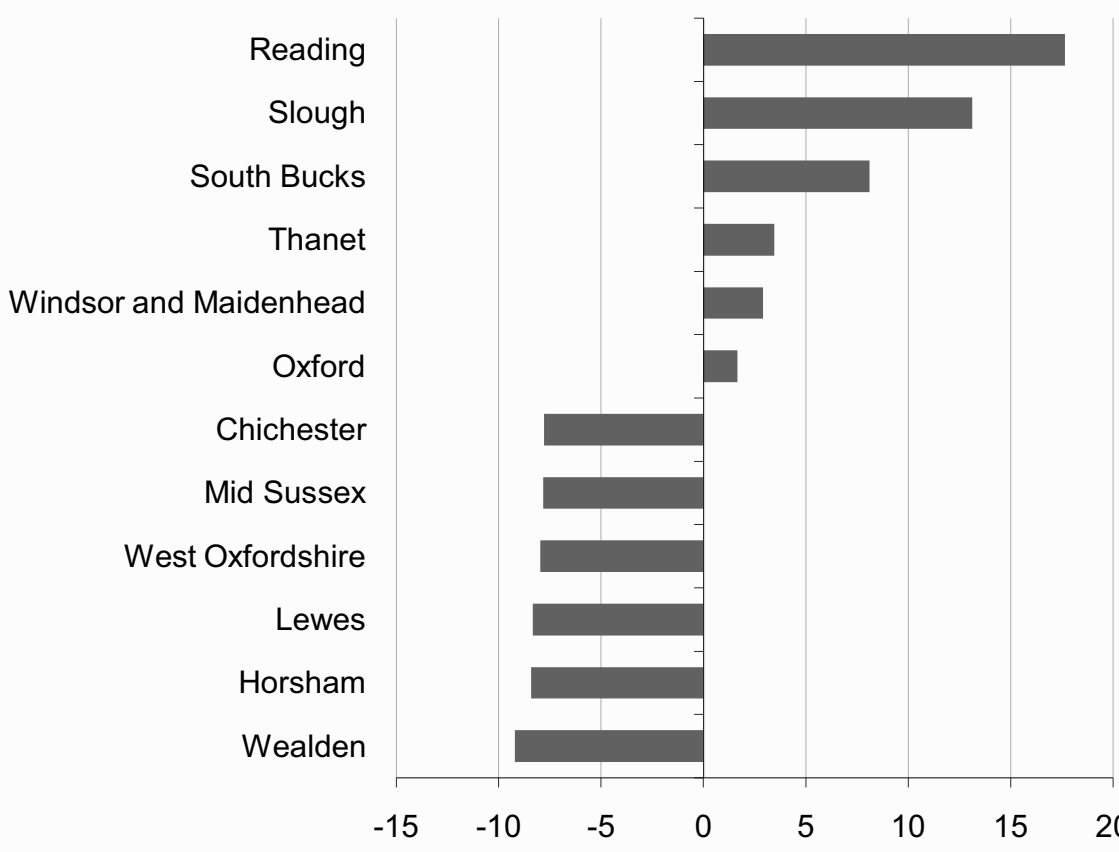

England and Wales $=11.6$

Source: Home Office

There were 17,000 police officers stationed in the South East in March 2009, which equated to one officer for every 493 residents. This is the second highest ratio of any region and 130 people per officer more than the UK average. The region continues to have the highest proportion of female officers of any region with 27.4 per cent. 


\section{Annex: Business stock}

In March 2010 there were almost 330,400 businesses in the South East that were registered for VAT and/or PAYE. There are additionally a similar number of businesses who will not be registered for either as they fall below the thresholds for these systems. While some of the differences in the number of businesses between districts are attributable to economic reasons, the size of each area is a major factor. Many businesses are quite small; across the South East 78 per cent of businesses employed four staff or fewer and just 5 per cent employed more than 20 people. Even for those businesses registered for VAT or PAYE, 70 per cent employed four staff or fewer, the second highest proportion (after London).

Relative to the population aged 16 and over, there were 483 business registered for VAT and/or PAYE per 10,000 adults in the South East at March 2010. On this measure, the lowest business density of any county area in the South East was 418 in Kent and Medway, whereas the highest was 601 per 10,000 adults in Buckinghamshire and Milton Keynes. The second lowest business density was in Hampshire and the Isle of Wight (422 per 10,000 adults). Within each county area there are wide variations in business density, the range for each area is represented by the dashed lines on each bar in Figure A1.

\section{Figure A1 Business ${ }^{1}$ density: by county ${ }^{2}$ area}

South East, March 2010

Business stock per 10,000 adults $^{3}$

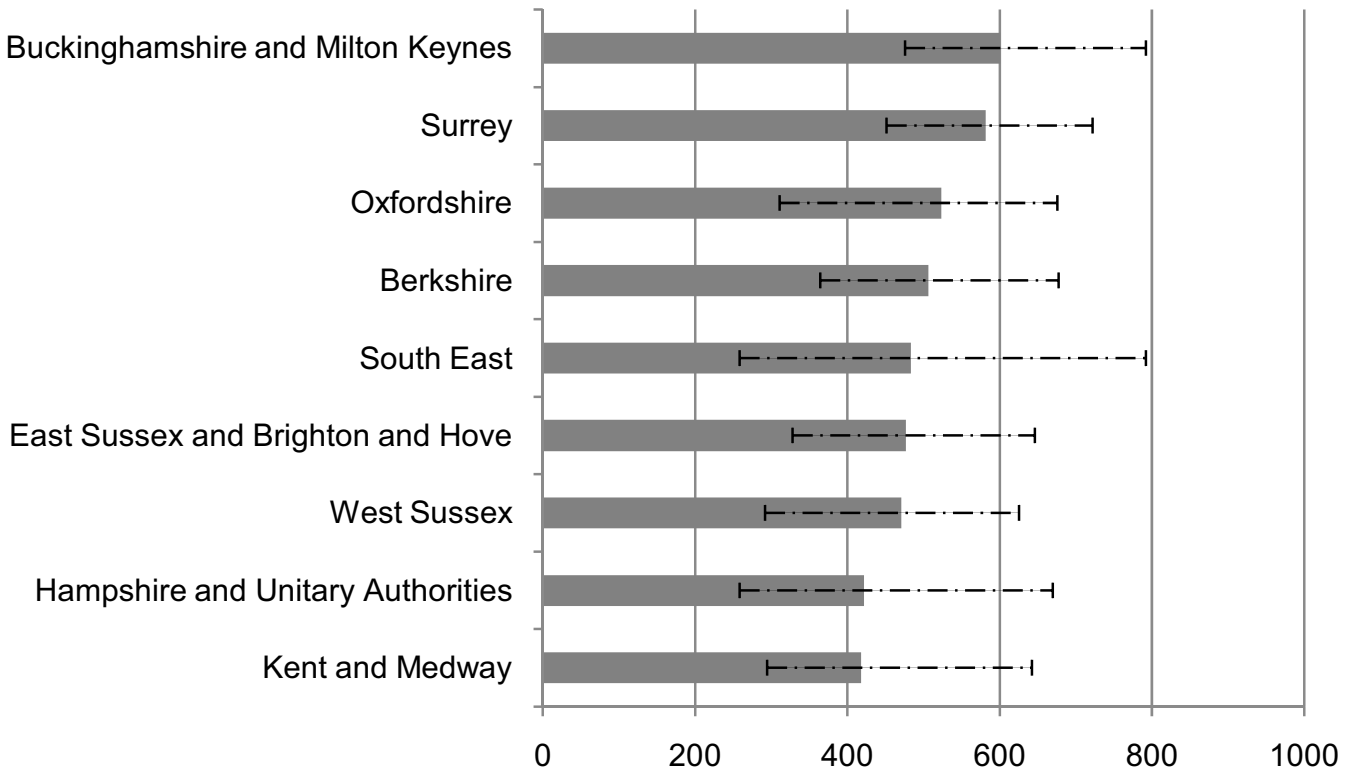

Note: Whiskers show the business density of the highest and lowest district/unitary authority in each area.

1 Businesses registered for VAT and/or PAYE.

2 County council plus unitary authority areas combined.

3 Mid-2009 resident population aged 16 or over.

Source: Office for National Statistics 
South Bucks had by far the highest number of business per 10,000 adults with 792 , followed by Chiltern with 727 (both in Buckinghamshire), whereas in Southampton and Gosport (Hampshire) there were about a third of this number with 258 businesses per 10,000 adults.

Another way of looking at business density is the number of registered businesses per square kilometre (sq km); the average for the South East was 17.3 in 2010. On this basis Oxfordshire had the lowest rate at 10.4, and Kent and Medway had the second lowest rate of 15.0 businesses per sq km. The highest number of businesses per sq $\mathrm{km}$ in the region was in Surrey at 31.4 per sq km. The geographical concentration of businesses highlights the commercial hubs of an area and also where there are greater opportunities for work, whereas a high density of businesses per resident adult can be an indicator of entrepreneurial activity.

\section{Map A2 Business births ${ }^{1}$ per 10,000 adults: by local or unitary authority ${ }^{2}$, 2009}
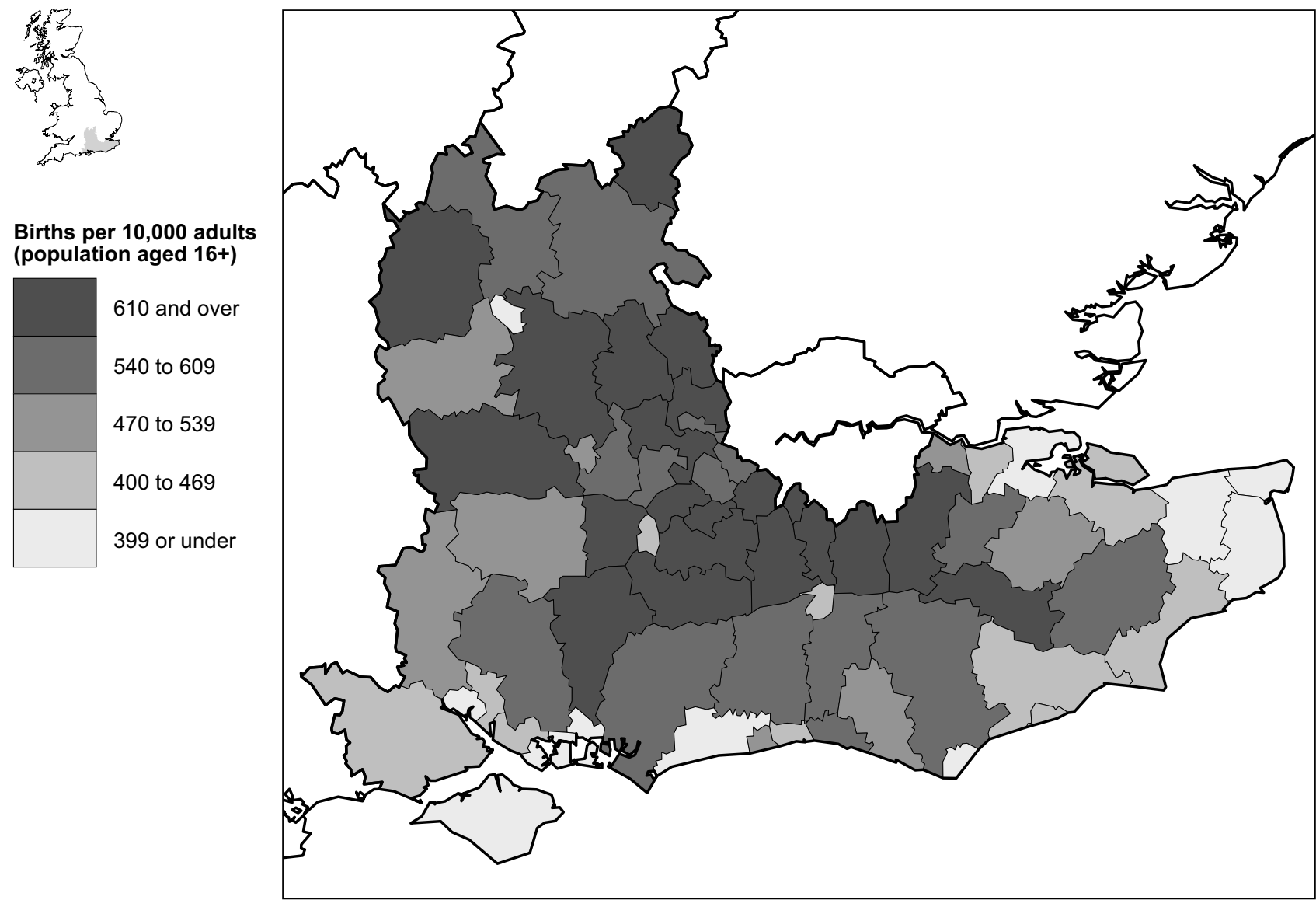

(c) Crown copyright and database right 2010. Ordnance Survey Licence 100019153.

1 New businesses registered for VAT and/or PAYE during the year.

2 For key to local authorities see Map A3.

Source: Office for National Statistics

During the course of any year new businesses are created and others cease to trade; areas with the highest business birth rates often also have the high death rates. This high level of 'churn' can be taken as an indication of economic activity and those areas with high birth and death rates tend to be where GVA is highest. In 2009 there were 36,320 business births in the South East, a decrease of 11 per cent on the number created the previous year. The number of business deaths 
showed an increase of 27 per cent compared with one year earlier and totalled 42,550 in 2009. This means that during the course of 2009 there was a net decrease of 6,230 businesses in the South East compared with a net increase of 6,555 the previous year. The greatest fall in number was in Brighton and Hove where there was a net decrease of more than 300 businesses. A decline was seen in most local authorities with only a handful, mainly in Oxfordshire, showing no net change or small increases.

Map A2 shows the number of business births per 10,000 adults for each district of the South East. Southampton had the lowest number of businesses created per resident adult, at 297 per 10,000 people aged 16 and over in 2009, whereas in South Bucks there were 1,026 new businesses started during the year for each 10,000 adults, more than twice the national average. Twenty-three districts and unitary authorities in the South East had business start-up rates below the national average of 470 per 10,000 people aged 16 and over. 


\section{Notes}

1. The authors wish to thank colleagues in the Centre for Regional and Local Statistics and the Mapping Unit in the Office for National Statistics (ONS) for help in producing this article.

2. The Glossary and Regional Trends Online Tables, where much of the data used in this article may be downloaded, are available through links at: www.statistics.gov.uk/regionaltrends/editions

3. For reference, the following map shows the names of the local and unitary authorities in the South East region.

\section{Map A3 Local authority districts and unitary authorities, April 2009}

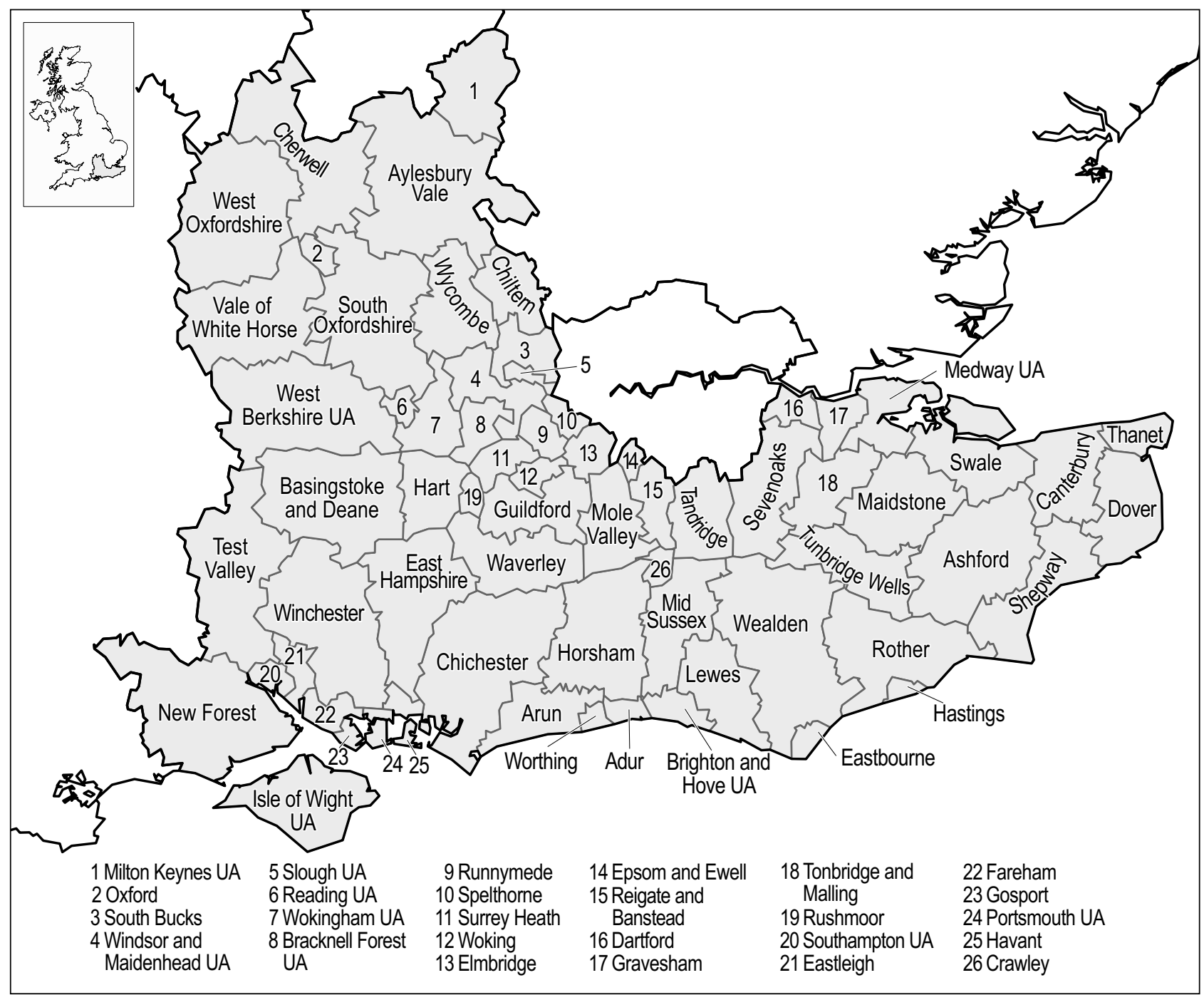

(c) Crown copyright and database right 2010. Ordnance Survey Licence 100019153. 